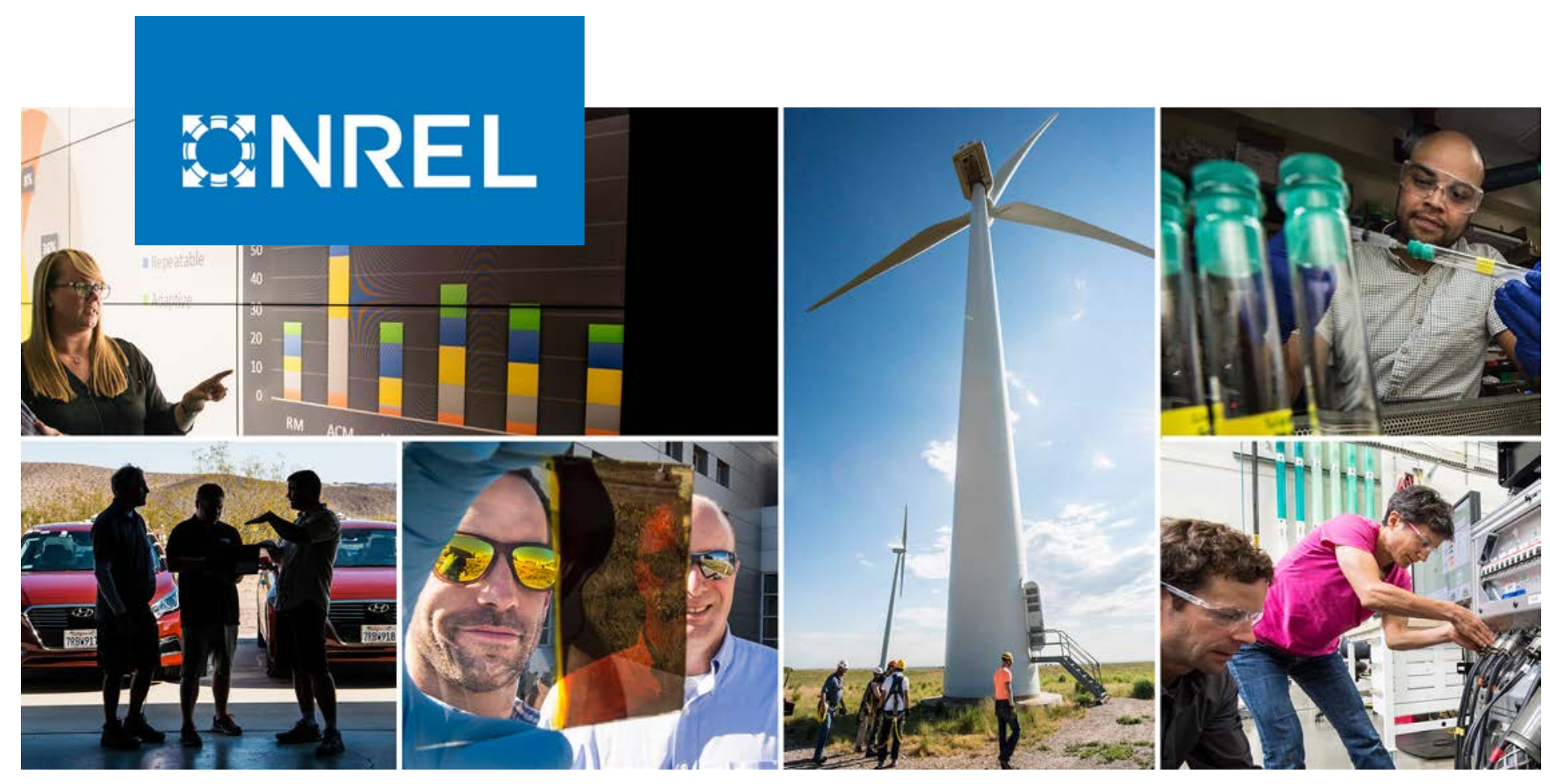

\title{
Reducing PV Performance Uncertainty by Accurately Quantifying the PV Resource
}

Yu Xie, Manajit Sengupta, Mike Dooraghi, and Aron Habte

National Renewable Energy Laboratory

NREL is a national laboratory of the U.S. Department of Energy

Office of Energy Efficiency \& Renewable Energy

Operated by the Alliance for Sustainable Energy, LLC

This report is available at no cost from the National Renewable Energy Laboratory (NREL) at www.nrel.gov/publications.

\section{Technical Report}

NREL/TP-5D00-73377

May 2019 


\title{
GNREL
}

\section{Reducing PV Performance Uncertainty by Accurately Quantifying the PV Resource}

\author{
Yu Xie, Manajit Sengupta, Mike Dooraghi, and Aron Habte
}

National Renewable Energy Laboratory

\section{Suggested Citation}

Xie, Yu, Manajit Sengupta, Mike Dooraghi, and Aron Habte. 2019. Reducing PV

Performance Uncertainty by Accurately Quantifying the PV Resource. Golden, CO:

National Renewable Energy Laboratory. NREL/TP-5D00-73377.

https://www.nrel.gov/docs/fy19osti/73377.pdf.

NREL is a national laboratory of the U.S. Department of Energy Office of Energy Efficiency \& Renewable Energy Operated by the Alliance for Sustainable Energy, LLC

This report is available at no cost from the National Renewable Energy Laboratory (NREL) at www.nrel.gov/publications.

Contract No. DE-AC36-08GO28308
Technical Report

NREL/TP-5D00-73377

May 2019

National Renewable Energy Laboratory 15013 Denver West Parkway Golden, CO 80401

303-275-3000 • www.nrel.gov 


\section{NOTICE}

This work was authored by the National Renewable Energy Laboratory, operated by Alliance for Sustainable Energy, LLC, for the U.S. Department of Energy (DOE) under Contract No. DE-AC36-08G028308. Funding provided by U.S. Department of Energy Office of Energy Efficiency and Renewable Energy Solar Energy Technologies Office. The views expressed herein do not necessarily represent the views of the DOE or the U.S. Government.

This report is available at no cost from the National Renewable Energy Laboratory (NREL) at www.nrel.gov/publications.

U.S. Department of Energy (DOE) reports produced after 1991 and a growing number of pre-1991 documents are available free via www.OSTI.gov.

Cover Photos by Dennis Schroeder: (clockwise, left to right) NREL 51934, NREL 45897, NREL 42160, NREL 45891, NREL 48097, NREL 46526.

NREL prints on paper that contains recycled content. 


$\begin{array}{ll}\text { List of Acronyms } \\ \text { AOD } & \text { Aerosol optical depth } \\ \text { APE } & \text { Absolute percentage error } \\ \text { BTDF } & \text { Bidirectional transmittance distribution function } \\ \text { DHI } & \text { Direct normal irradiance } \\ \text { DISC } & \text { Direct Insulation Simulation Code } \\ \text { DISORT } & \text { Discrete Ordinates Radiative Transfer } \\ \text { DNI } & \text { Direct normal irradiance } \\ \text { FARMS-NIT } & \text { Fast All-sky Radiation Model for Solar applications } \\ \text { FARMS-NIT } & \text { Fast All-sky Radiation Model for Solar applications with Narrowband } \\ & \text { Irradiances on Tilted surfaces } \\ \text { GHI } & \text { Global horizontal irradiance } \\ \text { MAE } & \text { Mean absolute error } \\ \text { MAPE } & \text { Mean absolute percentage error } \\ \text { MBE } & \text { Mean bias error } \\ \text { MPE } & \text { Mean percenter error } \\ \text { NREL } & \text { National Renewable Energy Laboratory } \\ \text { NSRDB } & \text { National Solar Radiation Database } \\ \text { PE } & \text { Percentage error } \\ \text { POA } & \text { Plane of array } \\ \text { PV } & \text { Photovoltaic } \\ \text { PWV } & \text { Precipitable water vapor } \\ \text { SAM } & \text { System Advisor Model } \\ \text { SMARTS } & \text { Simple Model of the Atmospheric Radiative Transfer of Sunshine } \\ \text { SRRL } & \text { Solar Radiation Research Laboratory } \\ \text { UV } & \text { Ultraviolet } \\ \text { WPVS } & \text { World Photovoltaic Scale Standard } \\ \end{array}$




\section{Executive Summary}

Reducing uncertainty in the prediction and/or verification of photovoltaic (PV) plant output can directly increase the expected return on investment for each party in a contract, likely leading to more favorable terms for the contract, including a possible reduction in interest rates. Note that a reduction of $1 \%$ in the interest rate is estimated to reduce the levelized cost of energy by approximately 0.5 cents/kWh (Branker, Pathak, and Pearce 2011). This project developed a capability to provide spectrally resolved solar information from the National Solar Radiation Data Base (NSRDB), effectively providing 20 years of half-hourly data for all of the United States at a 4-km by 4-km spatial resolution. These data are now available freely to users directly through a geographic information system-based Web interface (https://nsrdb.nrel.gov) as well as through an application programming interface (Sengupta et al. 2018; Xie and Sengupta 2018; Xie, Sengupta, and Dooraghi 2018; Xie, Sengupta, and Dudhia 2016). Users of these data can conduct more accurate prefeasibility studies and assess multiple PV technologies. It is expected that widely used models such as PVSyst, the National Renewable Energy Laboratory's System Advisor Model (SAM) (Blair et al. 2014), and PlantPredict, designed by First Solar, will develop the capabilities to use these spectral data.

For this project, we reduced the uncertainty in (1) predicting future PV plant performance and (2) assessing existing PV plant (hardware) performance. We accomplished this by (1) modeling (from satellite data) the spectrally weighted (to reflect the PV response) plane-of-array (POA) irradiance, which we refer to as the "PV resource," and creating and disseminating PV resource data sets to PV stakeholders; and (2) defining standard methods for quantifying the PV resource to verify system performance. We also created more accurate satellite-based PV resource data than shown by the results from current methods, thereby leading to a reduced price of solar electricity and increasing the expected return on investment of PV projects. The solar energy industry often uses individual steps to empirically compute the POA irradiance from horizontal irradiance and decompose it to narrow-wavelength bands. Conventional radiative transfer models designed for meteorological applications require significant computing efforts in practice; however, they provide a physics-based solution of radiance and therefore are capable of computing spectral POA irradiances in a single step (Ding et al. 2009; Lawless, Xie, and Yang et al. 2006; Xie, Sengupta, and Dhudia, 2006; Xie et al. 2012b).

In this study, we integrated the advantages of the current models and developed an innovative radiative transfer model, the Fast All-sky Radiation Model for Solar applications with Narrowband Irradiances on Tilted surfaces (FARMS-NIT), to efficiently compute irradiances on inclined PV panels for 2002 narrow-wavelength bands from 0.28 to $4.0 \mu \mathrm{m}$. For clear-sky conditions, the Simple Model of the Atmospheric Radiative Transfer of Sunshine (SMARTS) (Gueymard 1995) is employed to rapidly provide the optical properties of a given clear-sky atmosphere. The clear-sky radiances in the narrow-wavelength bands are computed by considering three paths of photon transmission and solving the radiative transfer equation with the single-scattering approximation. The bidirectional transmittance distribution function (BTDF) of aerosols is given by their single-scattering phase function with a correction using a two-stream approximation. The validation analysis confirms that FARMS-NIT has better accuracy than TMYSPEC as evaluated by both surface observations and a state-of-the-art radiative transfer model. This model substantially improves computational efficiency compared to other radiative transfer models even though it uses slightly more computing time than 
TMYSPEC. For cloudy-sky conditions, FARMS-NIT uses cloud reflectance of irradiance and BTDF from a precomputed lookup table by the LibRadtran model with a 32-stream Discrete Ordinates Radiative Transfer (DISORT) (Stamnes et al. 1988). The cloud reflectance and BTDF are combined with the clear-sky properties to efficiently compute spectral radiances on the land surface and POA irradiances. The PV resource has been developed by FARMS-NIT and disseminated by the NSRDB website. 


\section{Table of Contents}

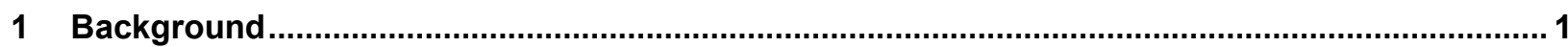

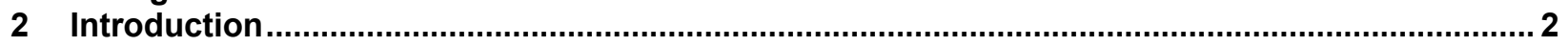

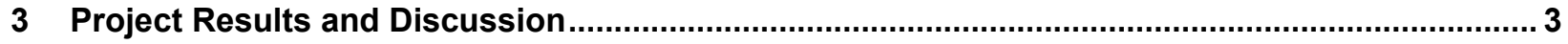

3.1 Development of FARMS-NIT ..................................................................................... 3

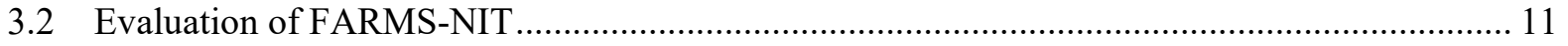

3.3 A New Algorithm to Evaluate Transposition Models Using FARMS-NIT .............................. 19

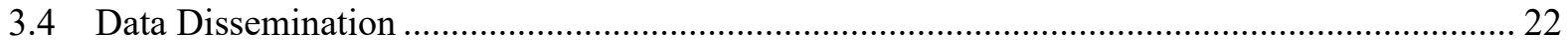

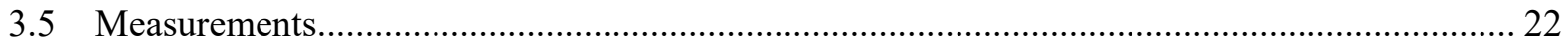

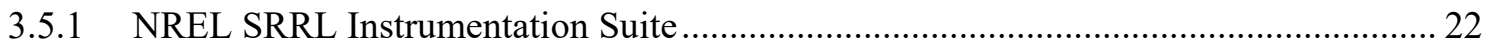

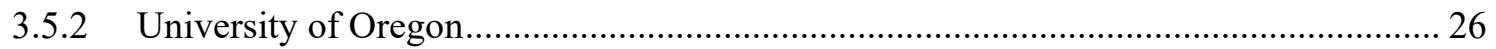

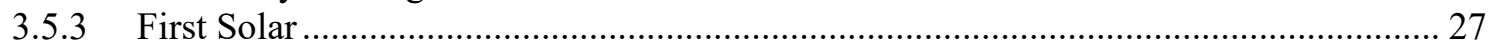

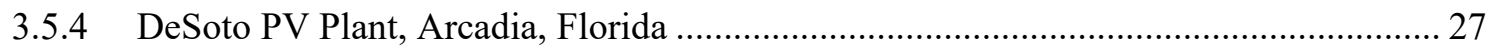

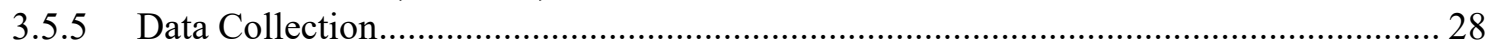

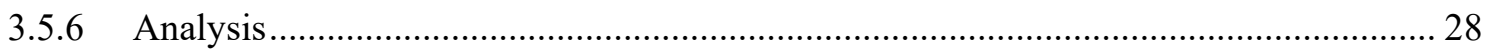

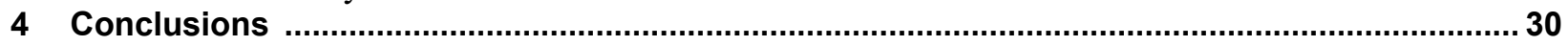

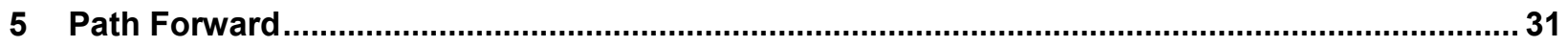

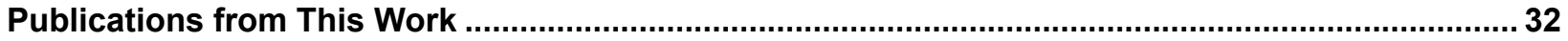

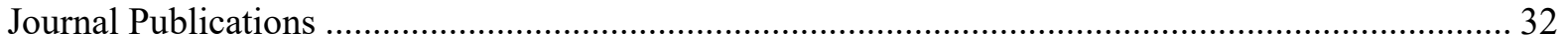

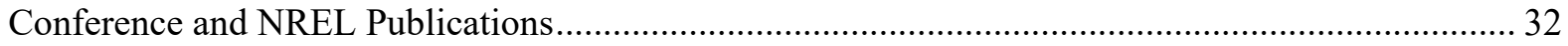

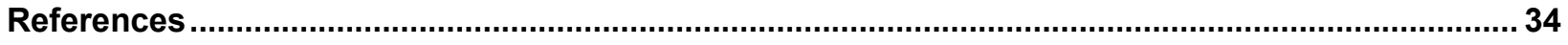




\section{List of Figures}

Figure 1. Geometry of a PV panel. XYZ represents a three-dimensional Cartesian coordinate on the horizontal surface. X'YZ' represents a three-dimensional Cartesian coordinate on the PV panel. The red beam represents a solar beam...................................................................... 3

Figure 2. A flowchart of the FARMS-NIT model for a clear-sky condition ............................................ 4

Figure 3. Partitioning transmittance of the atmosphere where solar radiation is (a) absorbed by the atmosphere and scattered by aerosol; (b) scattered in the atmosphere and scattered again by aerosol; and (c) scattered in the atmosphere and absorbed by aerosol................................... 6

Figure 4. $\boldsymbol{T F 0 u} / \boldsymbol{\omega} \mathbf{1}$ computed as a function of $\boldsymbol{\mu} \mathbf{0}$ and $\boldsymbol{\tau} \mathbf{1}$ using Eq. (19). $\boldsymbol{T F} \mathbf{0 u}$ is the diffuse transmittance of the clear atmosphere where the incident is direct radiation; $\boldsymbol{\omega} \mathbf{1}$ is the singlescattering albedo of the Rayleigh scattering; $\boldsymbol{\tau} \mathbf{1}$ is the optical thickness of the clean atmosphere. $\boldsymbol{\mu} \mathbf{0}$ is the cosine value of the solar zenith angle.

Figure 5. A flowchart of the FARMS-NIT model for a cloudy-sky condition ..................................... 10

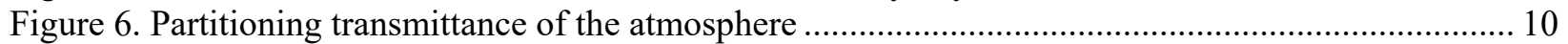

Figure 7. Spectral irradiances for a clean atmosphere over a horizontal surface computed by SMARTS and FARMS-NIT when (a) $\theta \_0=15^{\circ}$ and (b) $\theta \_0=60^{\circ}$. The red and blue lines represent the simulations by FARMS-NIT and SMARTS, respectively, and the black line....................... 11

Figure 8. Observations of GHI and cloud fraction at NREL on (a) October 20, 2017, and (b) January 22, 2018. Observations of AOD and surface albedo at NREL on (c) October 20, 2017, and (d) January 22, 2018.

Figure 9. Comparison of spectral POA irradiances computed by FARMS-NIT and TMYSPEC (a) at 10:05 a.m. on October 20, 2017, and (b) 12:00 p.m. on January 22, 2018. Difference between model simulation and NREL observations on a single-axis tracker (c) at 10:05 a.m. on October 20, 2017, and (d) 12:00 p.m. on January 22, 2018.

Figure 10. Comparison of spectral POA irradiances computed by FARMS-NIT, TMYSPEC, and DISORT at 12:00 p.m. on October 20, 2017, when the solar zenith angle is $50.447^{\circ}$. A PV panel is assumed facing south with a tilt angle of $30^{\circ}$.

Figure 11. Comparison of spectral POA irradiances computed by FARMS-NIT, TMYSPEC, and DISORT at 12:00 p.m. on October 20, 2017, when the solar zenith angle is $50.447^{\circ}$. A PV panel is assumed facing south with a tilt angle of $30^{\circ}$. 18

Figure 12. Computing time of hourly spectral POA irradiances during a day....................................... 18 Figure 13. A flowchart of computing POA irradiances using FARMS-NIT and transposition models. The blue boxes denote input data, the green boxes denote models, and the orange boxes denote results.

Figure 14. POA irradiances computed for (a) a clear-sky condition and cloudy-sky conditions with cloud optical thickness $\tau$ of (b) 3 and (c) 10. The sun is in the south with a zenith angle of $30^{\circ}$. A PV panel is facing south with various tilt angles. The DNIs in $(\mathrm{a}-\mathrm{c})$ are computed by the Beer-Bouguer-Lambert law. And $(\mathrm{d}-\mathrm{f})$ are the same as $(\mathrm{a}-\mathrm{c})$ except that DNI is computed using the DISC model.

Figure 15. POA irradiances when the sun is in the south with a zenith angle of $30^{\circ}$. The PV panel faces south, and $\beta=30^{\circ}$. DNI is computed by the (a) Beer-Bouguer-Lambert law and (b) DISC

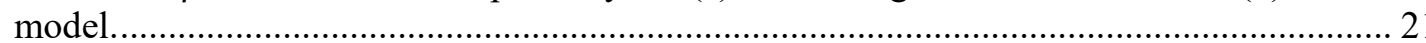

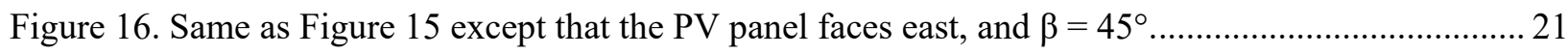

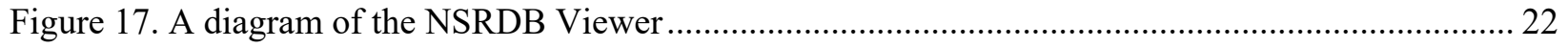

Figure 18. Instrumentation suite and POAs used in the SRRL PV resource study.................................23

Figure 19. Modification of LI-2020 two axis-trackers to operate as a one-axis tracker .......................... 24

Figure 20. The EKO STR-32G tracker operating in a one-axis motion and carrying the LI-1800 spectroradiometer.....

Figure 21. EKO STR-32G tracker modified to operate in one-axis tracking mode with WISER spectral system along with snippet of code used to control the STR-32G ........................................26 
Figure 22. STR-32G, modified to operate as a one-axis tracker with the WISER spectral system, two thermopiles, two reference cells, and four photodiodes...

Figure 23. Instrument configuration at the University of Oregon's Solar Radiation Monitoring Laboratory

Figure 24. Test setup at Desoto PV plant in Arcadia, Florida. The system included a thermopile, reference cell, and photodiode in the one-axis POA and a thermopile and photodiode in the GHI orientation.

Figure 25. Data can be compared between any of the three configurations at the SRRL (fixed tilt, global, one-axis) as well as with the University of Oregon (one-axis and GHI configurations). ...... 28

Figure 27. Ratios of GHI measurements to reference measurement on selected clear periods during the

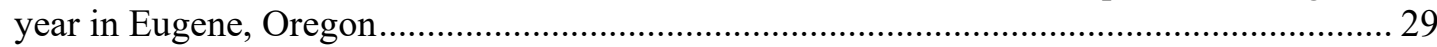

Figure 28. Comparison of the LI-200SA pyranometer and the RCO reference cell with the output of a

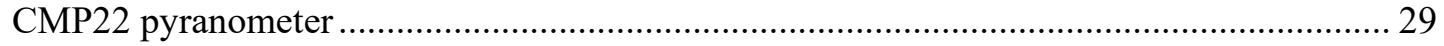

\section{List of Tables}

Table 1. MBE, MAE, PE, APE, MPE, and MAPE of Computed Spectral Irradiances in the POA Using FARMS-NIT and TMYSPEC

Table 2. Solar Monitoring Station Data from First Solar 


\section{Background}

The increasing use of solar energy as an alternative to conventional energy sources has boosted the demand to precisely measure or simulate the solar resource at the land surface. Solar radiation data are routinely provided on horizontal surfaces by ground- (Stokes and Schwartz 1994) and satellite-based observations (Sengupta et al. 2014; Sengupta et al. 2018; Xie, Sengupta, and Dudhia 2016) in a broadband-wavelength range from $0.2-5 \mu \mathrm{m}$ because approximately $99 \%$ of the total solar radiation on the Earth's surface lies within this region (Liou 2002).

Quantification of solar radiation in narrow-wavelength bands plays a crucial role in solar energy research because the efficiency of photovoltaic (PV) systems is dominated by the spectral distribution of incident solar radiation, the spectral response of semiconductor materials, and the solar cell designs to split the spectral radiation (Fahrenbruch and Bube 1983; Mojiri et al. 2013). Although high-spectralresolution models designed for meteorological applications-e.g., the line-by-line model (Clough et al. 2005) - are capable of computing spectral solar radiation based on fundamental physics, they are often time-consuming when solving the absorption coefficients of the molecular species in the atmosphere. Thus, models parameterizing the computation of absorption and scattering - e.g., the Simple Model of the Atmospheric Radiative Transfer of Sunshine (SMARTS) (Gueymard 1995), SUNSPEC (McCluney and Gueymar 1993), and TMYSPEC (Myers 2012) - were developed to provide efficient solutions of spectral radiation and thus are more applicable to solar energy applications.

At the land surface, three solar sources contribute to plane-of-array (POA) irradiances in broad or narrow-wavelength bands: direct radiation, diffuse radiation from sky, and diffuse radiation from the land surface (Xie, Sengupta, and Dooraghi 2018). Transposition models, which convert horizontal irradiance to the POA, simulate the contribution from diffuse radiation by following empirical regression analyses (hereafter referred to as empirical models) based on long-term observations of diffuse horizontal irradiance and POA irradiances in various orientations (Perez et al. 1990; Reindl, Beckman, and J. Duffie 1990) or by assuming that diffuse radiation is isotropic over the sky dome (hereafter referred to as isotropic models) (Badescu 2002; Liu and Jordan 1961). Compared to empirical models, isotropic models underestimate the strong forward scattering by clouds or aerosols (Xie 2010; Xie et al. 2011; Xie et al. 2009; Xie et al. 2012a), and thus they are likely to underestimate POA irradiance on 1- or 2-axis tracking PV panels; however, the performance of empirical models depends on the localized atmospheric and land surface conditions as well as solar and PV orientations (Xie, Sengupta, and Dooraghi 2018). Xie, Sengupta, and Dooraghi (2018) demonstrated that POA irradiance can be calculated using the spatial distribution of radiances that are computed by one-dimensional radiative transfer models designed for meteorological purposes. 


\section{Introduction}

Xie, Sengupta, and Dhudia (2016) developed the Fast All-sky Radiation Model for Solar applications (FARMS), which uses the parameterization of clear-sky radiation and physics-based solutions of cloud transmittance and reflectance to efficiently compute broadband global horizontal irradiance (GHI) and direct normal irradiance (DNI). This study intends to expand the capability of FARMS and develop a new radiative transfer model, FARMS with Narrowband Irradiances on Tilted surfaces (FARMS-NIT), which integrates the advantages in the existing models used for meteorological and solar energy purposes. This new model is based on the efficient computation of spectral radiances at the land surface, which simultaneously leads to POA irradiances in numerous narrow-wavelength bands.

A number of studies have use surface observations to assess the performance of transposition models (Gueymard 1987; Gueymard and Ruiz-Arias 2016; Jakhrani et al. 2012; Kamali, Moradi, and Khalili 2006; Khalili and Shaffie 2013; Lave et al. 2015; Loutzenhiser et al. 2007; Noorian, Moradi, Kamali 2008; Pandey and Katiyar 2009). A significant uncertainty of those studies is that the limited availability of surface observations restricts the analysis with limited temporal and spatial domains. Thus, there exists a need to analyze the transposition models in a broader context and systematically understand their reliability under varying meteorological conditions. To achieve this goal, we proposed new algorithms to evaluate transposition models using both measurements and modeling tools. We first reviewed the analytical derivation of POA irradiance and its numerical solution based on transposition models. The surface-based observations taken at the National Renewable Energy Laboratory's (NREL's) Solar Radiation Research Laboratory (SRRL) are used to compare simulations from the isotropic models, an empirical model, and FARMS-NIT. FARMS-NIT computes POA irradiance under extensive atmospheric conditions and can be used to analyze the transposition models and explore the physical sources of their uncertainties. 


\section{Project Results and Discussion}

\subsection{Development of FARMS-NIT}

Figure 1 shows the geometry of a PV panel.

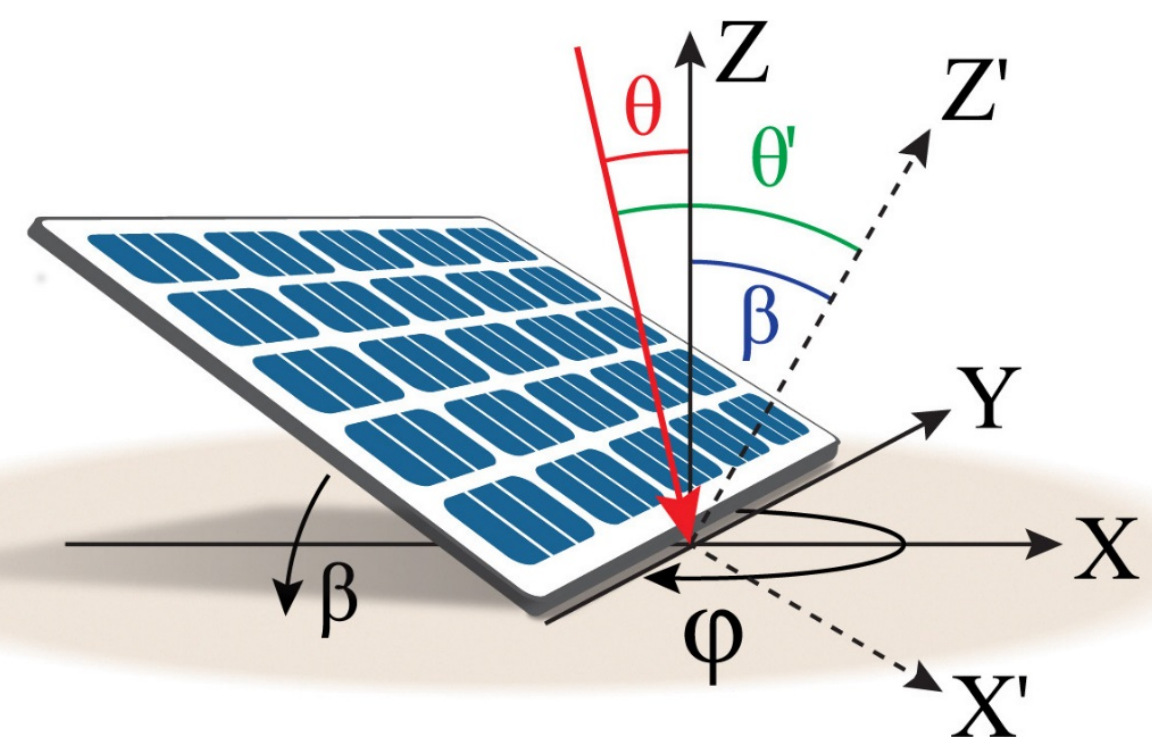

Figure 1. Geometry of a PV panel. XYZ represents a three-dimensional Cartesian coordinate on the horizontal surface. X'YZ' represents a three-dimensional Cartesian coordinate on the PV panel. The red beam represents a solar beam.

A spectral POA irradiance over a monofacial PV panel can be given by:

$$
\mathrm{POAI}=\mathrm{POAI}_{\mathrm{d}}+\mathrm{POAI}_{\mathrm{u}, \mathrm{sky}}+\mathrm{POAI}_{\mathrm{u}, \text { ground }}
$$

where $\mathrm{POAI}_{\mathrm{d}}, \mathrm{POAI}_{\mathrm{u}, \mathrm{sky}}$, and $\mathrm{POAI}_{\mathrm{u} \text {,ground }}$ are the spectral POA irradiances associated with direct irradiance, diffuse irradiance from sky, and diffuse irradiance from ground reflection, respectively (Gueymard 1987; Jakhrani et al. 2012; Loutzenhiser et al. 2007; Noorian, Moradi, and Kamali 2008; Xie, Sengupta, and Dooraghi 2018).

According to Xie, Sengupta, and Dooraghi (2018) and the references citied therein, $\mathrm{POAI}_{\mathrm{d}}, \mathrm{POAI}_{\mathrm{u}, \mathrm{sky}}$, and $\mathrm{POAI}_{\mathrm{u}, \text { ground }}$ can be computed by:

$$
\begin{gathered}
\text { POAI }_{\mathrm{d}}=\mathrm{DNI}_{\cos \theta^{\prime}} \\
\text { POAI }_{\mathrm{u}, \mathrm{sky}}=\int_{0}^{2 \pi} \int_{0}^{\Theta(\beta, \varphi)} \mathrm{I}_{\mathrm{t}} \cos \theta^{\prime} \sin \theta \mathrm{d} \theta \mathrm{d} \varphi \\
\text { POAI }_{\mathrm{u}, \text { ground }}=\int_{0}^{2 \pi} \int_{0}^{\frac{\pi}{2}-\Theta(\beta, \varphi)} \mathrm{I}_{\mathrm{r}} \cos \theta^{\prime} \sin \theta \mathrm{d} \theta \mathrm{d} \varphi,
\end{gathered}
$$


where DNI denotes direct normal irradiance; $\mathrm{I}_{\mathrm{t}}$ is the diffuse radiance from the sky; $\mathrm{I}_{\mathrm{r}}$ is the reflected radiance by the land surface; $\theta^{\prime}$ is the angle between the incident solar beam and the normal direction of the inclined PV panel; $\theta$ is the zenith angle; $\varphi$ is the azimuth angle; $\beta$ is the title angle of the PV panel; and $\Theta(\beta, \varphi)$ represents the upper limit of $\theta$ for each $\varphi$ that can be given by:

$$
\Theta(\beta, \varphi)=\left\{\begin{array}{c}
\frac{\pi}{2} \text { when }-\frac{\pi}{2} \leq \varphi \leq \frac{\pi}{2} \\
\frac{\pi}{2}-\tan ^{-1}(-\tan \beta \cos \varphi) \text { when } \frac{\pi}{2} \leq \varphi \leq \frac{3 \pi}{2}
\end{array}\right.
$$

Thus, POA irradiance can be computed by Eq. (2) without any approximation when $\mathrm{I}_{\mathrm{t}}$ and $\mathrm{I}_{\mathrm{r}}$ are known. Figure 2 denotes a flowchart showing the computation of clear-sky POA irradiance by FARMS-NIT.

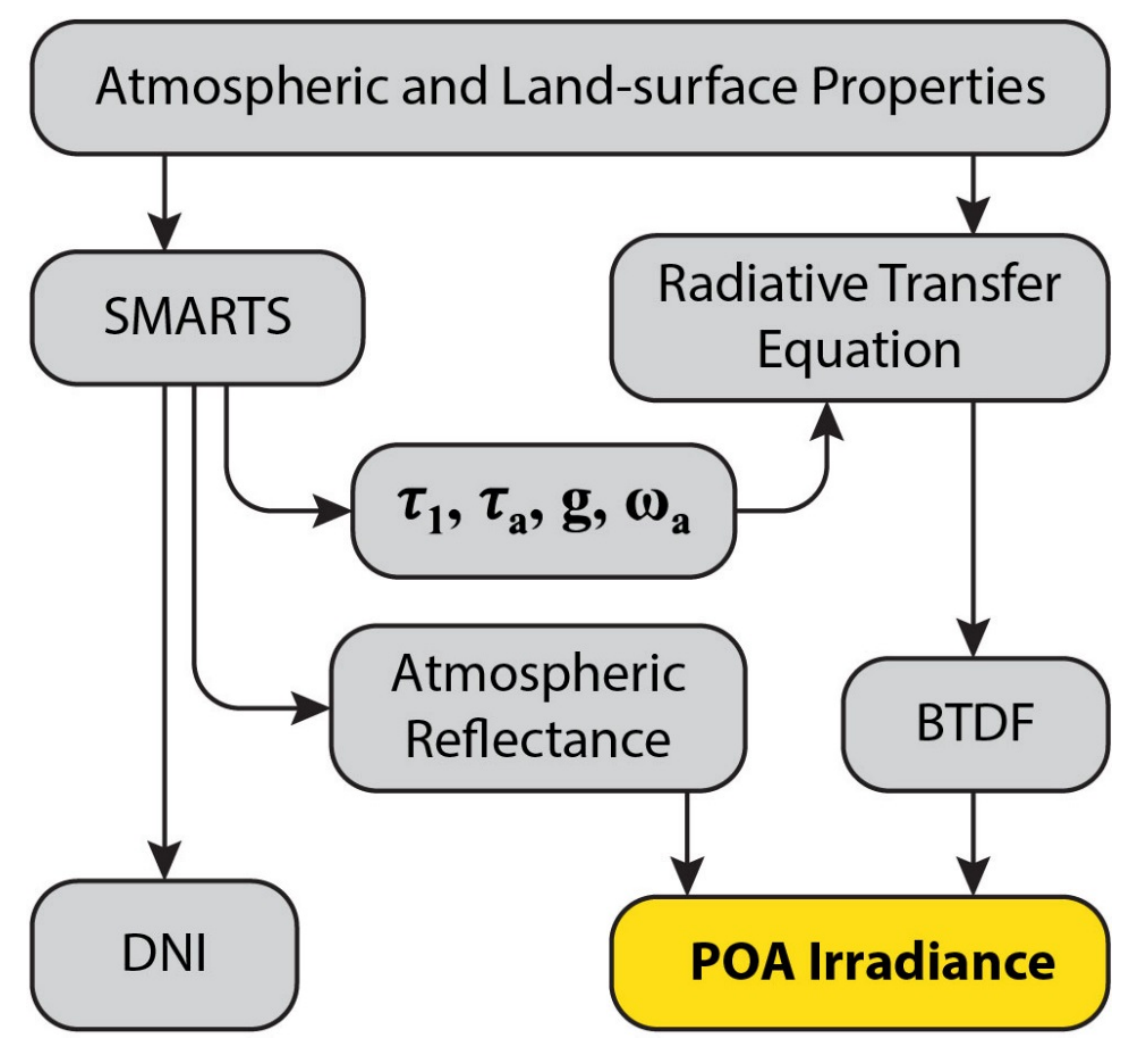

Figure 2. A flowchart of the FARMS-NIT model for a clear-sky condition

To compute $\mathrm{I}_{\mathrm{t}}$ and $\mathrm{I}_{\mathrm{r}}$, we assume a homogeneous aerosol layer in the atmosphere around the land surface. Therefore, the atmosphere can be divided into two layers: the aerosol layer and the atmosphere above it. For DNI, we follow the solutions from SMARTS, version 2.9.5, (Gueymard 1995), which parameterizes the spectral transmission of direct solar radiation under clear-sky conditions. With users' input of atmospheric profile and aerosol information, SMARTS can also compute the reflectance of the atmosphere; the total optical thickness of all trace gases, $\tau_{1}$; aerosol optical depth (AOD), $\tau_{\mathrm{a}}$; and the single-scattering albedo, $\omega_{\mathrm{a}}$, and factor, $\mathrm{g}$, of the aerosol. The computed optical thickness of trace gases and aerosol properties in spectral bands are then input to the radiative transfer equation and used to solve the bidirectional transmittance distribution function (BTDF) of the clear atmosphere. Therefore, the spectral region and resolution of FARMS-NIT follows SMARTS, which covers 2002 narrow- 
wavelength bands within $0.28-4.0 \mu \mathrm{m}$, and uses intervals of $0.5 \mathrm{~nm}, 1 \mathrm{~nm}$, and $5 \mathrm{~nm}$ in $0.28-0.3995 \mu \mathrm{m}$, 0.4-1.7 $\mu \mathrm{m}$, and 1.705-4.0 $\mu \mathrm{m}$, respectively (Gueymard 1995).

The diffuse radiances at the land surface are computed by:

$$
\begin{aligned}
\mathrm{I}_{\mathrm{t}}\left(\mu_{\mathrm{t}}, \varphi_{\mathrm{t}}\right) & =\mathrm{I}_{0}\left(\mathrm{TF}_{1}+\mathrm{TF}_{2}\right) \\
\mathrm{I}_{0} & =\frac{\mu_{0} \mathrm{~F}_{0}}{\pi},
\end{aligned}
$$

where $\mathrm{TF}_{1}$ is the $\mathrm{BTDF}$ for the first-order radiation; $\mathrm{TF}_{2}$ is the $\mathrm{BTDF}$ for radiances related to multiple reflection between aerosols and the land surface; $\mu_{0}$ is the cosine value of the solar zenith angle; and $\mathrm{I}_{0}$ and $\mathrm{F}_{0}$ are the extraterrestrial solar radiance and irradiance, respectively.

The optical thickness of the Rayleigh scattering is very small, especially in the near-infrared and infrared regions $(\lambda>0.7 \mu \mathrm{m})$. Thus, the scattering events in the clean atmosphere-i.e., cloud and aerosol freeare assumed as single scattering. The effect of multiple scattering in the ultraviolet (UV) and visible regions is considered and discussed in the next section.

Wang et al. (2013) derived the bidirectional reflectance distribution function (BRDF) of the atmosphere from six possible paths of photon transmission. Following the Rayleigh scattering correction technique and the study of Wang et al. (2013), $\mathrm{TF}_{1}$ can be solved from three independent events (see Figure 3 ) where photons are (1) absorbed by the atmosphere and scattered by aerosol, (2) scattered in the atmosphere and scattered again by aerosol, and (3) scattered in the atmosphere and absorbed by aerosol. Thus, $\mathrm{TF}_{1}$ is given by:

$$
\begin{gathered}
\mathrm{TF}_{1}=\mathrm{TF}_{1 \mathrm{a}}+\mathrm{TF}_{1 \mathrm{~b}}+\mathrm{TF}_{1 \mathrm{c}} \\
\mathrm{TF}_{1 \mathrm{a}}=\exp \left(-\frac{\tau_{1}}{\mu_{0}}\right) \mathrm{TF}_{0 \mathrm{t}}^{\mathrm{a}} \\
\mathrm{TF}_{1 \mathrm{~b}}=\frac{\omega_{1}}{4 \pi} \int_{0}^{2 \pi} \int_{0}^{1} \frac{\mu_{\mathrm{j}}}{\mu_{\mathrm{j}}-\mu_{0}} \mathrm{P}_{0 \mathrm{j}} \mathrm{TF}_{\mathrm{jt}}^{\mathrm{a}}\left[\exp \left(-\frac{\tau_{1}}{\mu_{\mathrm{j}}}\right)-\exp \left(-\frac{\tau_{1}}{\mu_{0}}\right)\right] \mathrm{d} \mu_{\mathrm{j}} \mathrm{d} \varphi_{\mathrm{j}} \\
\mathrm{TF}_{1 \mathrm{c}}=\frac{\omega_{1} \mathrm{P}_{0 \mathrm{t}}}{4\left(\mu_{\mathrm{t}}-\mu_{0}\right)} \exp \left(-\frac{\tau_{\mathrm{a}}}{\mu_{\mathrm{t}}}\right)\left[\exp \left(-\frac{\tau_{1}}{\mu_{\mathrm{t}}}\right)-\exp \left(-\frac{\tau_{1}}{\mu_{0}}\right)\right],
\end{gathered}
$$

where $\mathrm{TF}_{1 \mathrm{a}}, \mathrm{TF}_{1 \mathrm{~b}}$, and $\mathrm{TF}_{1 \mathrm{c}}$ represent $\mathrm{TF}_{1}$ for the independent events; $\mathrm{TF}_{0 \mathrm{t}}^{\mathrm{a}}$ and $\mathrm{TF}_{\mathrm{jt}}^{\mathrm{a}}$ are $\mathrm{BTDFs}$ of the aerosol; $\mathrm{P}_{0 \mathrm{j}}$ and $\mathrm{P}_{0 \mathrm{t}}$ are the single-scattering phase functions of the Rayleigh scattering; $\omega_{1}$ is the singlescattering albedo of the Rayleigh scattering in the atmosphere; $\mu$ is the cosine value of zenith angle; and the subscripts, " $\mathrm{j}$ ", " 0 ", and "t" represent the photon direction after the scattering and the solar incident and outgoing directions, respectively. 

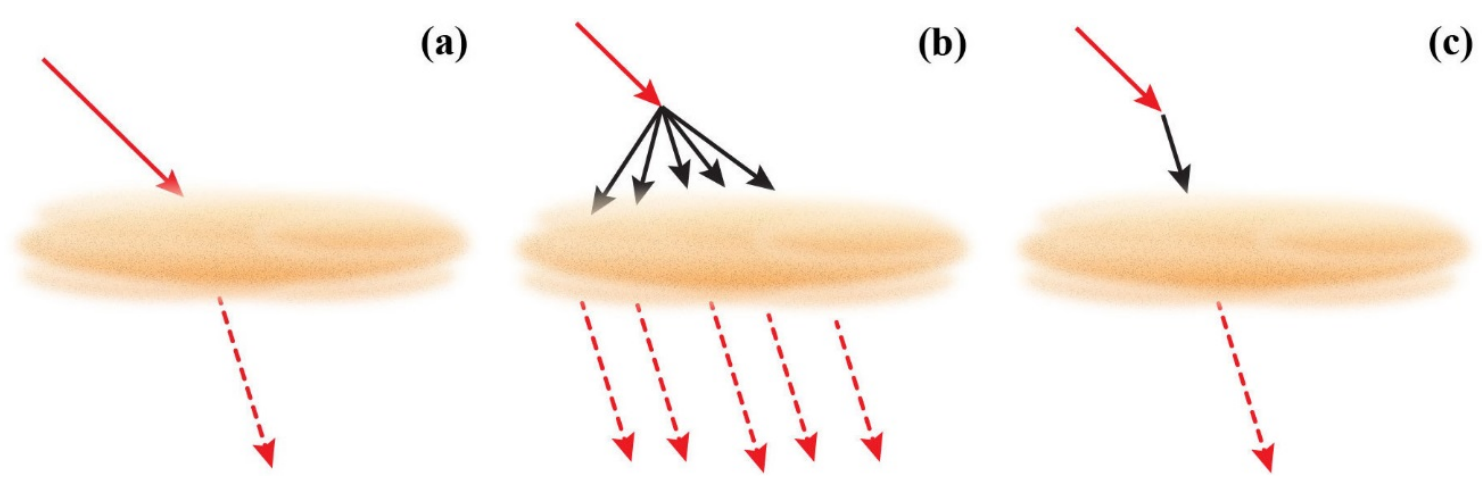

Figure 3. Partitioning transmittance of the atmosphere where solar radiation is (a) absorbed by the atmosphere and scattered by aerosol; (b) scattered in the atmosphere and scattered again by aerosol; and (c) scattered in the atmosphere and absorbed by aerosol.

With the assumption that energy is conserved in the Rayleigh scattering process, $\omega_{1}$ can be approximated by Wang et al. (2013):

$$
\omega_{1}=\frac{\tau_{\mathrm{R}}}{\tau_{1}}
$$

where $\tau_{R}$ is the optical thickness associated with the Rayleigh scattering. $P_{0 j}$ and $P_{0 t}$ are given by the phase function of the Rayleigh scattering (Liou 2002):

$$
P_{0 j}=\frac{3}{4}\left(1+\cos ^{2} \Theta_{0 j}\right)
$$

and:

$$
\mathrm{P}_{0 \mathrm{t}}=\frac{3}{4}\left(1+\cos ^{2} \Theta_{0 \mathrm{t}}\right)
$$

where $\Theta_{0 \mathrm{j}}$ and $\Theta_{0 \mathrm{t}}$ are the scattering angles according to the photon incident and outgoing directions. For backward scattering, $\Theta_{0 \mathrm{j}}$ and $\Theta_{0 \mathrm{t}}$ are given by:

$$
\cos \Theta_{0 j}=-\mu_{0} \mu_{j}+\left(1-\mu_{0}^{2}\right)^{1 / 2}\left(1-\mu_{j}^{2}\right)^{1 / 2} \cos \varphi_{0 j}
$$

and:

$$
\cos \Theta_{0 \mathrm{t}}=-\mu_{0} \mu_{\mathrm{t}}+\left(1-\mu_{0}^{2}\right)^{1 / 2}\left(1-\mu_{\mathrm{t}}^{2}\right)^{1 / 2} \cos \varphi_{0 \mathrm{t}}
$$

where $\varphi_{0 \mathrm{j}}$ and $\varphi_{0 \mathrm{t}}$ denote the relative azimuth angle between the photon incident and outgoing directions. For forward scattering, $\Theta_{0 j}$ and $\Theta_{0 t}$ are given by:

$$
\cos \Theta_{0 j}=\mu_{0} \mu_{j}+\left(1-\mu_{0}^{2}\right)^{1 / 2}\left(1-\mu_{j}^{2}\right)^{1 / 2} \cos \varphi_{0 j}
$$

and:

$$
\cos \Theta_{0 \mathrm{t}}=\mu_{0} \mu_{\mathrm{t}}+\left(1-\mu_{0}^{2}\right)^{1 / 2}\left(1-\mu_{\mathrm{t}}^{2}\right)^{1 / 2} \cos \varphi_{0 \mathrm{t}},
$$

Because aerosols in the atmosphere are optically very thin, we assume single scattering within the aerosol layer as the first-order approximation. Under this assumption, $\mathrm{TF}_{0 \mathrm{t}}^{\mathrm{a}}$ and $\mathrm{TF}_{\mathrm{jt}}^{\mathrm{a}}$ can be given as: 


$$
\begin{aligned}
& \mathrm{TF}_{0 \mathrm{t}}^{\mathrm{a}}=\frac{\omega_{\mathrm{a}}}{4} \mathrm{P}_{0 \mathrm{t}}^{\mathrm{a}} \frac{1}{\mu_{0}-\mu_{\mathrm{t}}}\left[\exp \left(-\frac{\tau_{\mathrm{a}}}{\mu_{0}}\right)-\exp \left(-\frac{\tau_{\mathrm{a}}}{\mu_{\mathrm{t}}}\right)\right] \\
& \mathrm{TF}_{\mathrm{jt}}^{\mathrm{a}}=\frac{\omega_{\mathrm{a}}}{4} \mathrm{P}_{\mathrm{jt}}^{\mathrm{a}} \frac{1}{\mu_{\mathrm{j}}-\mu_{\mathrm{t}}}\left[\exp \left(-\frac{\tau_{\mathrm{a}}}{\mu_{\mathrm{j}}}\right)-\exp \left(-\frac{\tau_{\mathrm{a}}}{\mu_{\mathrm{t}}}\right)\right],
\end{aligned}
$$

where $P_{0 j}^{a}$ and $P_{j t}^{a}$ are the single-scattering phase functions of aerosol that can be approximated by the asymmetric factor of aerosol, g, and Henyey-Greenstein phase function:

$$
\begin{aligned}
& \mathrm{P}_{0 \mathrm{t}}^{\mathrm{a}}=\frac{1-\mathrm{g}^{2}}{\left(1+\mathrm{g}^{2}-2 \mathrm{~g} \cos \Theta_{0 \mathrm{t}}\right)^{3 / 2}} \\
& \mathrm{P}_{\mathrm{jt}}^{\mathrm{a}}=\frac{1-\mathrm{g}^{2}}{\left(1+\mathrm{g}^{2}-2 \mathrm{~g} \cos \Theta_{\mathrm{jt}}\right)^{3 / 2}} .
\end{aligned}
$$

The asymmetric factors of aerosol are following the results from SMARTS for all the narrow bands.

For computing $\mathrm{TF}_{2}$, the first-order downwelling irradiance is derived as

$$
F_{1}=F_{d}+\int_{0}^{2 \pi} \int_{0}^{1} I_{0} T_{1} \mu_{t} d \mu_{t} d \varphi_{t},
$$

where $F_{d}$ represents direct radiation on the horizontal surface. The total downwelling irradiance is then:

$$
\mathrm{F}_{\text {total }}=\mathrm{F}_{1}+\mathrm{F}_{1} \mathrm{R}_{\mathrm{s}} \mathrm{R}_{\mathrm{uu}}+\mathrm{F}_{1} \mathrm{R}_{\mathrm{s}} \mathrm{R}_{\mathrm{uu}} \mathrm{R}_{\mathrm{s}} \mathrm{R}_{\mathrm{uu}}+\ldots=\mathrm{F}_{1}\left(1-\mathrm{R}_{\mathrm{s}} \mathrm{R}_{\mathrm{uu}}\right)^{-1},
$$

where $R_{s}$ is the land-surface albedo, and $R_{u u}$ is the clear-sky reflectance of irradiance that is computed by SMARTS. Then, $\mathrm{TF}_{2}$ can be derived as follows:

$$
\begin{gathered}
\mu_{0} \mathrm{~F}_{0} \mathrm{TF}_{2}=\mathrm{F}_{\text {total }}-\mathrm{F}_{1}=\frac{\mathrm{R}_{\mathrm{s}} \mathrm{R}_{\mathrm{uu}}}{1-\mathrm{R}_{\mathrm{s}} \mathrm{R}_{\mathrm{uu}}} \mathrm{F}_{1} \\
\mathrm{TF}_{2}=\frac{\mathrm{R}_{\mathrm{s}} \mathrm{R}_{\mathrm{uu}}}{1-\mathrm{R}_{\mathrm{s}} \mathrm{R}_{\mathrm{uu}}} \frac{\mathrm{F}_{1}}{\mu_{0} \mathrm{~F}_{0}} .
\end{gathered}
$$

With the assumption of a Lambertian surface, the reflected radiance by the land surface can be computed by:

$$
\mathrm{I}_{\mathrm{r}}=\frac{\mathrm{F}_{\text {total }} R_{\mathrm{s}}}{\pi}
$$

In this derivation of $\mathrm{TF}_{1}$, we assume that the Rayleigh scattering in the atmosphere and the light scattering within the aerosol are single-scattering events; however, the optical thickness related to the Rayleigh scattering might not be very small in certain UV and visible regions. To account for the effect of multiple scattering because of the Rayleigh scattering, the single-scattering albedo of the clean atmosphere in Eq. (6) is adjusted to: 


$$
\omega_{1}=\frac{\tau_{\mathrm{R}}}{\tau_{1}} \mathrm{M},
$$

where $\mathrm{M}$ is a scaling factor for multiple scattering that is given by:

$$
\mathrm{M}=\left\{\begin{array}{c}
1 \text { when } 0.28 \mu \mathrm{m} \leq \lambda \leq 0.3 \mu \mathrm{m} \text { or } 0.7 \mu \mathrm{m} \leq \lambda \leq 4.0 \mu \mathrm{m} \\
1.6232711 \tau_{\mathrm{R}}+1.0439955 \text { when } 0.3 \mu \mathrm{m}<\lambda<0.7 \mu \mathrm{m}
\end{array} .\right.
$$

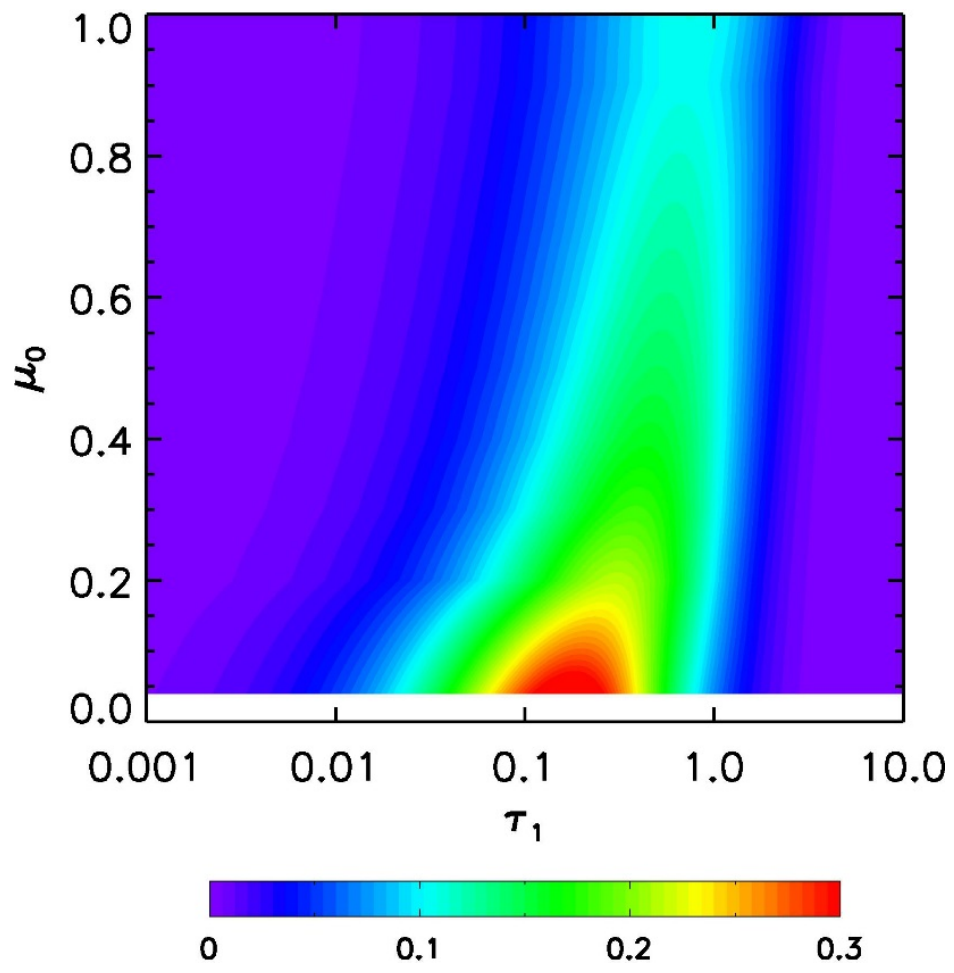

Figure 4. $T F_{0 u} / \omega_{1}$ computed as a function of $\mu_{0}$ and $\tau_{1}$ using Eq. (19). $T F_{0 u}$ is the diffuse transmittance of the clear atmosphere where the incident is direct radiation; $\omega_{1}$ is the single-scattering albedo of the Rayleigh scattering; $\tau_{1}$ is the optical thickness of the clean atmosphere. $\mu_{0}$ is the cosine value of the solar zenith angle.

Moreover, the amount of aerosol over desert or high-polluted areas can be significant, which also leads to multiple scattering of solar radiation within the aerosol. To account for this effect, we consider the two-stream approximation provided by Meador and Weaver (1980) where a thin layer transmittance of irradiance is given by:

$$
\mathrm{T}_{0 \mathrm{u}}^{\mathrm{a}}=1-\frac{\tau_{\mathrm{a}}}{\mu_{0}}\left[1+\omega_{\mathrm{a}}(0.5-0.5 \mathrm{~g})-\omega_{\mathrm{a}}\right]-\exp \left(-\frac{\tau_{\mathrm{a}}}{\mu_{0}}\right) .
$$

To make the GHI consistent with the two-stream approximation, Eq. (9a) and Eq. (9b) are adjusted by:

$$
\begin{aligned}
& \mathrm{TF}_{0 \mathrm{t}}^{\mathrm{a}}{ }^{\prime}=\frac{\omega_{\mathrm{a}}}{4} \mathrm{P}_{0 \mathrm{t}}^{\mathrm{a}} \frac{1}{\left(\mu_{0}-\mu_{\mathrm{t}}\right)}\left[\exp \left(-\frac{\tau_{\mathrm{a}}}{\mu_{0}}\right)-\exp \left(-\frac{\tau_{\mathrm{a}}}{\mu_{\mathrm{t}}}\right)\right] \frac{\mathrm{T}_{0 \mathrm{u}}^{\mathrm{a}}}{\mathrm{T}^{\mathrm{a}}} \\
& \mathrm{TF}_{\mathrm{jt}}^{\mathrm{a}{ }^{\prime}}=\frac{\omega_{\mathrm{a}}}{4} \mathrm{P}_{\mathrm{jt}}^{\mathrm{a}} \frac{1}{\left(\mu_{\mathrm{j}}-\mu_{\mathrm{t}}\right)}\left[\exp \left(-\frac{\tau_{\mathrm{a}}}{\mu_{\mathrm{j}}}\right)-\exp \left(-\frac{\tau_{\mathrm{a}}}{\mu_{\mathrm{t}}}\right)\right] \frac{\mathrm{T}_{0 \mathrm{u}}^{\mathrm{a}}}{\mathrm{T}^{\mathrm{a}}},
\end{aligned}
$$


where $\mathrm{T}^{\mathrm{a}}$ is the diffuse transmittance of aerosol computed by integrating the BTDF from Eq. (9a):

$$
\mathrm{T}^{\mathrm{a}}=\int_{0}^{2 \pi} \int_{0}^{1} \mathrm{TF}_{0 \mathrm{t}}^{\mathrm{a}} \mu_{\mathrm{t}} \mathrm{d} \mu_{\mathrm{t}} \mathrm{d} \varphi_{\mathrm{t}} .
$$

From the derivation above, the computation of atmospheric transmission and reflection has been substantially simplified compared to the solutions of the radiative transfer equation with the multiple scattering term (Liou 2002). Some approximations and simplifications can be made to further reduce the computing burden of the model.

In the previous equations, we used $\mu=1.0,0.96,0.92, \ldots, 0.0$, and $\varphi=0^{\circ}, 10^{\circ}, 20^{\circ}, \ldots, 360^{\circ}$ for the numerical computation of the integrals. They are determined to best balance the computational efficiency and the accuracy in representing the integrals. The uncertainty associated with this selection will be further discussed in Part II (the companion paper).

Because of the double integration loop in Eq. (5b), the computation of $\mathrm{TF}_{1 \mathrm{~b}}$ consumes most of the computational efforts of the FARMS-NIT. To simplify Eq. (5b), we assume that the solar radiation through the Rayleigh scattering in Figure $3 \mathrm{~b}$ is isotropic and that the downwelling irradiance is the same with the rigorous solution of the Rayleigh scattering. Then, $\mathrm{TF}_{1 \mathrm{~b}}$ can be approximated by:

$$
\mathrm{TF}_{1 \mathrm{~b}}=\mathrm{TF}_{0 \mathrm{u}} \mathrm{T}_{\mathrm{uu}}^{\mathrm{a}}
$$

where $\mathrm{T}_{\mathrm{uu}}^{\mathrm{a}}$ is the transmittance of aerosol for diffuse radiation. $\mathrm{TF}_{0 \mathrm{u}}$ is the diffuse transmittance of the clean atmosphere (aerosol free) where the incident is direct radiation. Thus, it can be given by the expression of $\mathrm{TF}_{1 \mathrm{~b}}$ when $\mathrm{TF}_{\mathrm{jt}}^{\mathrm{a}}=1$ for all directions:

$$
\mathrm{TF}_{0 \mathrm{u}}=\frac{\omega_{1}}{4 \pi} \int_{0}^{2 \pi} \int_{0}^{1} \frac{\mu_{\mathrm{j}}}{\mu_{\mathrm{j}}-\mu_{0}} \mathrm{P}_{0 \mathrm{j}}\left[\exp \left(-\frac{\tau_{1}}{\mu_{\mathrm{j}}}\right)-\exp \left(-\frac{\tau_{1}}{\mu_{0}}\right)\right] \mathrm{d} \mu_{\mathrm{j}} \mathrm{d} \varphi_{\mathrm{j}} .
$$

To reduce the computational time, $\mathrm{TF}_{0 \mathrm{u}} / \omega_{1}$ is precomputed for all possible $\mu_{0}$ and $\tau_{1}$ using Eq. (19). For given atmospheric information, $\mathrm{TF}_{0 \mathrm{u}}$ can then be rapidly checked from the results using $\tau_{1}$ and $\omega_{1}$ provided by SMARTS. Figure 4 illustrates the computed $\mathrm{TF}_{0 \mathrm{u}} / \omega_{1}$ as a function of $\mu_{0}$ and $\tau_{1}$. It shows that when the atmosphere is optically thin, the diffuse transmittance increases with solar zenith angle because of the more significant Rayleigh scattering. When the optical thickness of the atmosphere is much greater than 1, the diffuse transmittance is almost negligible because of the stronger absorption in the atmosphere. $\mathrm{T}_{\mathrm{uu}}^{\mathrm{a}}$ used by Eq. (18) can be computed by:

$$
\mathrm{T}_{\mathrm{uu}}^{\mathrm{a}}=\frac{2 \pi \int_{0}^{1} \mu \mathrm{IT}_{0 \mathrm{u}}^{\mathrm{a}} \mathrm{d} \mu}{\pi \mathrm{I}}=2 \int_{0}^{1} \mu \mathrm{T}_{0 \mathrm{u}}^{\mathrm{a}} \mathrm{d} \mu,
$$

where I represents the diffuse radiance above the aerosol, and $\mathrm{T}_{0 \mathrm{u}}^{\mathrm{a}}$ is given by Eq. (15). 


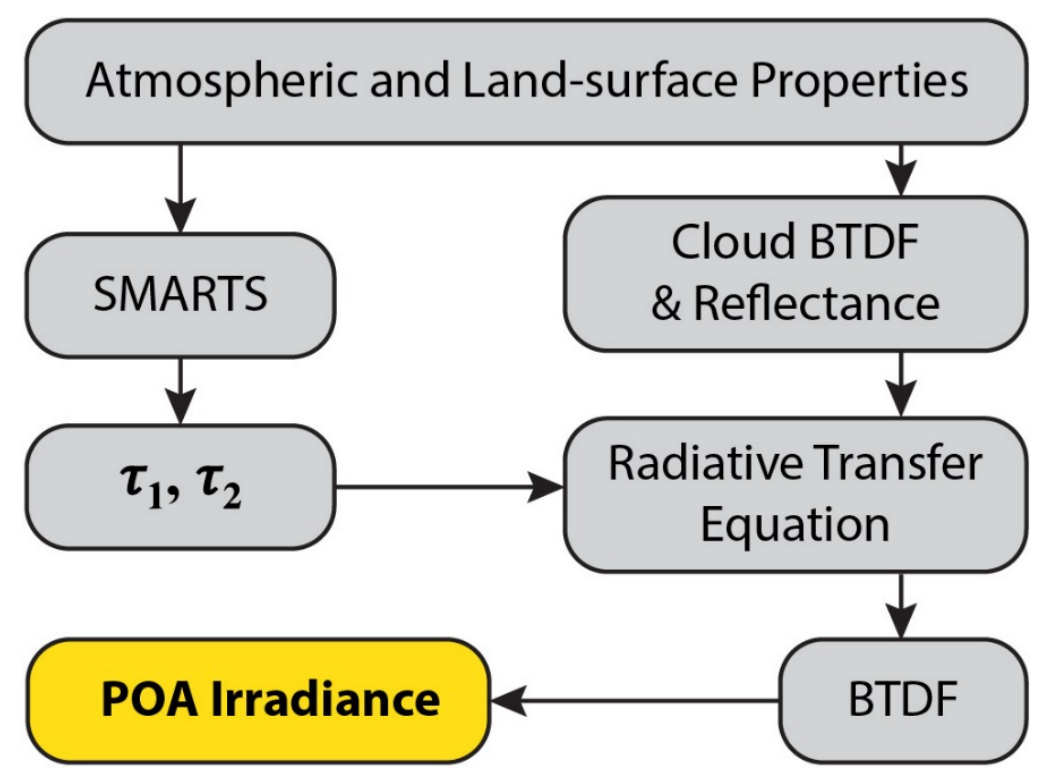

Figure 5. A flowchart of the FARMS-NIT model for a cloudy-sky condition

Figure 5 is a flowchart showing the scheme of computing cloudy-sky POA irradiance by FARMS-NIT. We assume a homogeneous cloud in the atmosphere, which is then vertically divided into three layers: the upper sky, the cloud, and the lower sky. Similar to the clear-sky model, SMARTS, version 2.9.5, is used to provide the reflectance of the atmosphere as well as the optical thicknesses of the upper and lower sky in 2002 wavelength bands within $0.28-4.0 \mu \mathrm{m}$. The BTDF of cloud is given by a precomputed lookup table for all possible cloud conditions.
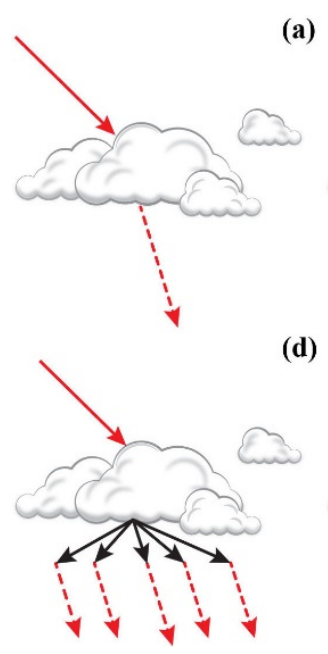

(a)

(d)
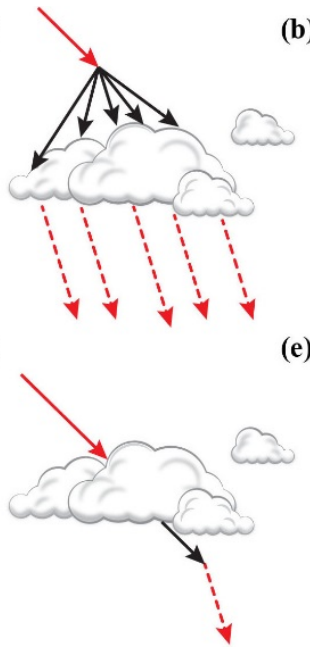

(b)

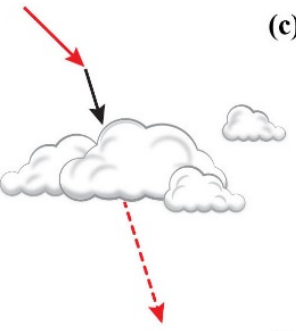

(e)

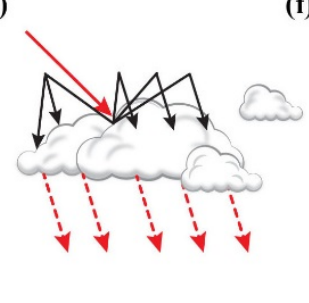

(c)

(f)

Figure 6. Partitioning transmittance of the atmosphere

Following the Rayleigh scattering correction technique, solar radiance under a cloudy-sky condition is related to six independent events (see Figure 6) where photos are (a) absorbed in the upper sky, scattered by the cloud, and absorbed in the lower sky; (b) scattered in the upper sky, scattered by the cloud, and absorbed in the lower sky; (c) scattered in the upper sky, absorbed by the cloud, and absorbed by the lower sky; (d) absorbed in the upper sky, scattered by the cloud, and scattered in the lower sky; (e) absorbed in the upper sky, absorbed by the cloud, and scattered in the lower sky; and (f) absorbed in the 
upper sky, reflected by the cloud, scattered in the upper sky, scattered by the cloud, and absorbed in the lower sky. Because the sixth photon path is associated with three scattering events, the transmitted radiation is negligible compared to the first five photon paths. We compute the solar radiance by solving the radiative transfer equation with the single-scattering approximation for the five individual paths.

\subsection{Evaluation of FARMS-NIT}

Following these discussions, SMARTS can provide the optical properties of trace gases and aerosols in the atmosphere based on a predeveloped parameterization and a given atmospheric profile. SMARTS also parameterizes the absorption by the molecular species, Rayleigh scattering, atmospheric reflection, and land-surface reflection and efficiently uses them to compute spectral irradiance on the land surface. FARMS-NIT employs the optical properties of the atmosphere from SMARTS, solves the radiative transfer equation with the single-scattering approximation, and computes radiances for various orientations.
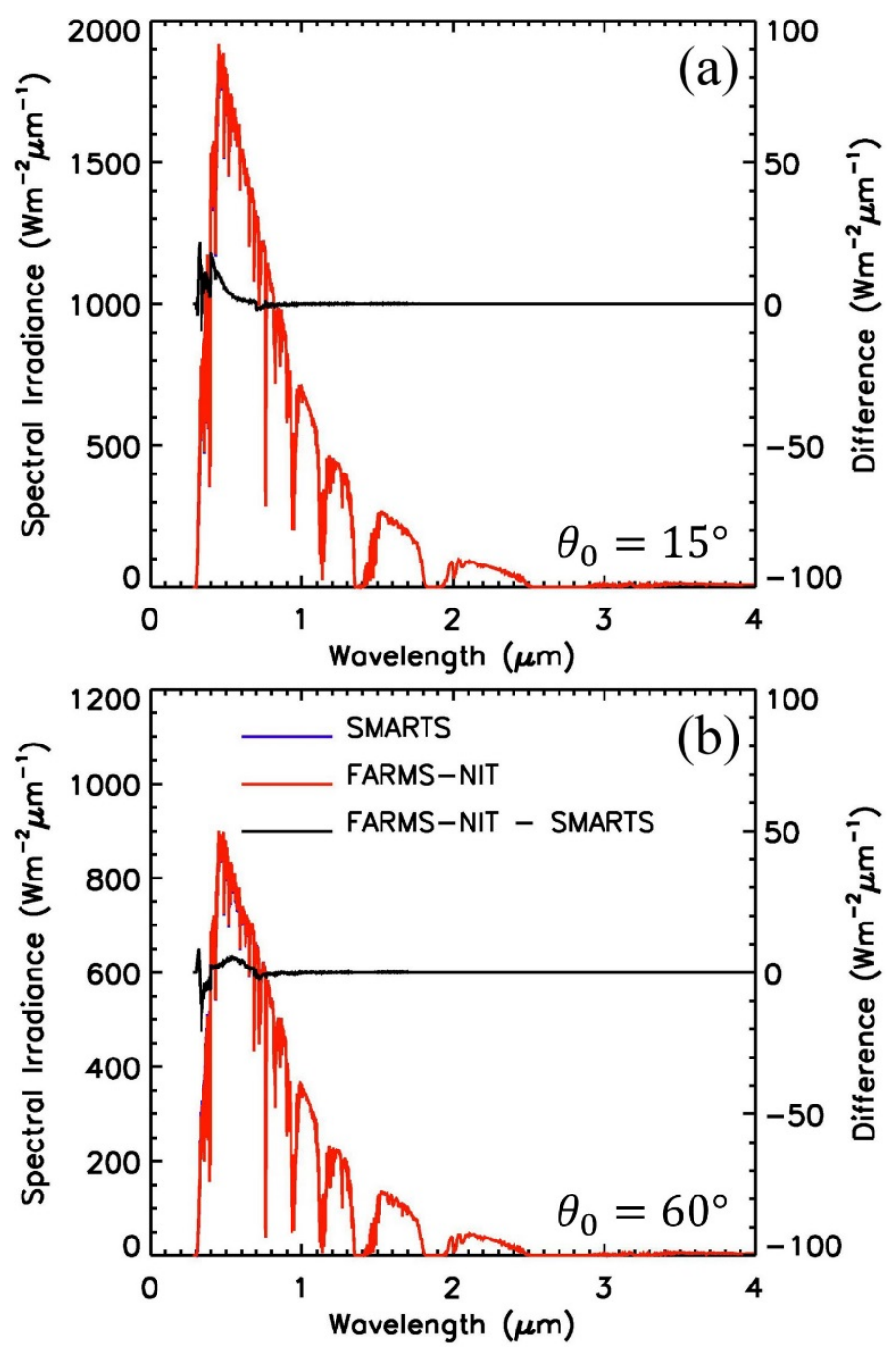

Figure 7. Spectral irradiances for a clean atmosphere over a horizontal surface computed by SMARTS and FARMS-NIT when (a) $\theta \_0=15^{\circ}$ and (b) $\theta \_0=60^{\circ}$. The red and blue lines represent the simulations by FARMS-NIT and SMARTS, respectively, and the black line denotes their difference. 
Although SMARTS and FARMS-NIT use completely different approaches to account for the light scattering in the atmosphere, their differences should be significantly reduced when the thickness of aerosols is negligible. Further, the computation of multiple scattering by FARMS-NIT is improved by a correction using SMARTS. Thus, it is important to first evaluate FARMS-NIT using SMARTS with a clean atmosphere-i.e., clouds and aerosols are absent in the atmosphere.

Figure 7 shows spectral irradiances of a clean atmosphere on a horizontal surface when solar zenith angles, $\theta_{0}$, are $15^{\circ}$ and $60^{\circ}$. The atmospheric properties follow the 1976 U.S. Standard Atmosphere. The figure shows that FARMS-NIT has an excellent agreement with SMARTS for all wavelengths even though they use different schemes to calculate the Rayleigh scattering. The majority of the differences are localized in the UV regions because of the considerable optical thickness of the Rayleigh scattering. For the smaller solar zenith angle, FARMS-NIT gives slightly larger irradiances than SMARTS, whereas the reverse is observed in the larger solar zenith angle. The maximum differences between FARMS-NIT and SMARTS are about $20 \mathrm{Wm}^{-2} \mu \mathrm{m}^{-1}$.

To further understand the performance of FARMS-NIT, we compare model simulation with surface observation from NREL's SRRL. Figure 8a and Figure $8 \mathrm{~b}$ demonstrate measured GHI by a Kipp \& Zonen CM Pyranometer 22 (CMP22) and cloud fraction from a Yankee total sky imager on October 20, 2017 , and January 22, 2018. Scenes corresponding to a smooth GHI curve and cloud fractions smaller than 20\% (those in the gray shadow in Figure 8) are selected for the clear-sky computation. Surface observations of precipitable water vapor measured by a Zephyr Geodetic Global Positioning System antenna, AOD estimated by a seven-channel Prede POM-01 photometer, and land surface albedo from an inverted CMP21 are used as inputs to FARMS-NIT (Figure 8c and Figure 8d). As shown in Figure $8 \mathrm{~d}$, a day with a snow land surface (with very large surface albedos) is compared with a day when the land is covered by bare soil and vegetation (Figure 8c). 

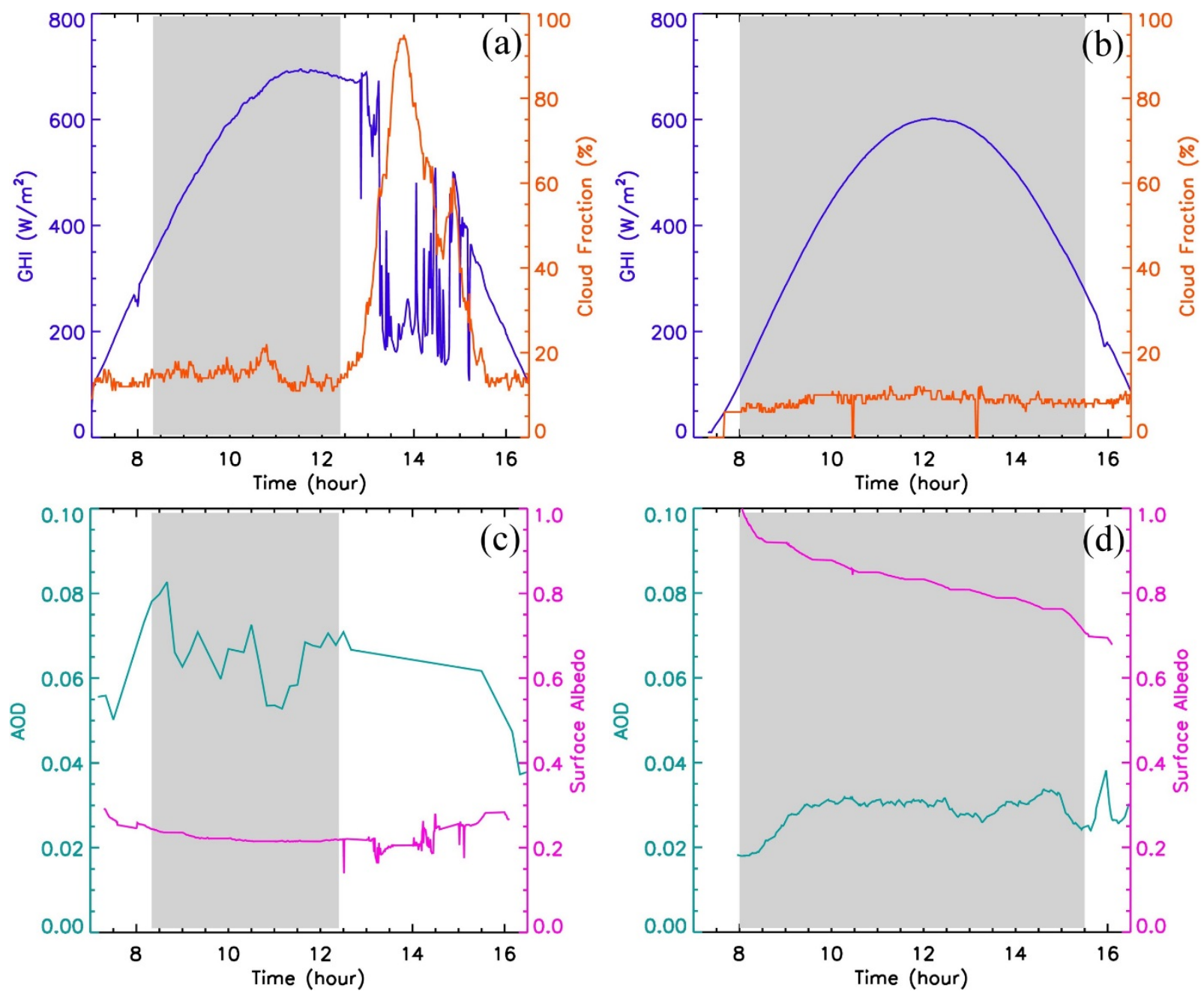

Figure 8. Observations of GHI and cloud fraction at NREL on (a) October 20, 2017, and (b) January 22, 2018. Observations of AOD and surface albedo at NREL on (c) October 20, 2017, and (d) January $22,2018$.

FARMS-NIT employs SMARTS to compute the optical properties of aerosol, which provides 12 choices of aerosol models introduced by Shettle and Fenn (1979), IAMAP (1986, WMO/TD-No. 24), and Braslau and Dave (1973). The AODs in the narrow-wavelength bands are computed using the given aerosol model, AOD in the wavelength of $0.55 \mu \mathrm{m}$, and the Ångström's turbidity formula (Liou 2002). In this study, we select the rural aerosol model given by Shettle and Fenn (1979) because of the low concentration of soot and sea salt particles in the atmosphere over NREL's SRRL. The model simulation by FARMS-NIT is then validated by surface observation from an EKO WISER spectroradiometer system on a single-axis tracker at NREL's SRRL that covers the wavelengths from $0.35-1.65 \mu \mathrm{m}$ in 1nm intervals (1301 wavelength bands).

For comparison with the FARMS-NIT simulations, we use the TMYSPEC model (Myers 2012) to compute spectral irradiances in the wavelengths from $0.3-1.8 \mu \mathrm{m}$ in 10-nm intervals (151 wavelength bands). The measured GHI and DNI computed by the Direct Insulation Simulation Code (DISC) model (Maxwell 1987) are used as the input data to TMYSPEC. Unlike FARMS-NIT, TMYSPEC combines multiple steps and empirically determines regressions to compute spectral POA irradiances from broadband GHI, DNI, and other atmospheric properties. It computes spectral irradiances in clear-sky 
conditions by best matching surface observations from a LI-COR model LI-1800 spectrometer (Nann and Riordan 1991). The spectral irradiances over tilted surfaces are corrected according to a broadband transposition model developed by Perez et al. (1987). The spectral irradiances in cloudy-sky conditions are estimated by the clear-sky irradiances and an empirically determined cloud-cover modifier. More details about TMYSPEC can be found in Myers (2012).

Figures $9 \mathrm{a}$ and $9 \mathrm{~b}$ illustrate the model simulations from FARMS-NIT and TMYSPEC. Compared to the 151 wavelength bands of TMYSPEC, the 2002 bands of FARMS-NIT demonstrate many more details of the atmospheric absorption by molecular species, e.g., the strong absorption by oxygen at the wavelength of $0.76 \mu \mathrm{m}$ is more obvious from the results of FARMS-NIT. The model simulations and surface observations are averaged in each 20-nm interval within $0.3-1.65 \mu \mathrm{m}$ (66 intervals), and their differences are compared (Figure 9c and Figure 9d). FARMS-NIT better represents the peak of spectral radiation in the visible region, but it tends to overestimate the solar radiation in the UV region; however, TMYSPEC also underestimates spectral radiation in the UV region with the same order of magnitude. Note that the validation study of SMARTS also demonstrated significant uncertainties in the wavelengths of $0.3-0.55 \mu \mathrm{m}$ (Gueymard 1995). Thus, future studies on improving trace gas measurements and the simulation of the atmospheric absorption are needed for both SMARTS and FARMS-NIT. For land surface covered by snow, FARMS-NIT has much better performance than TMYSPEC because it efficiently uses the observations of surface albedo and thus better simulates the diffuse radiation from the land surface (Figure 9d). This is also obvious in the mean bias error (MBE), mean absolute error (MAE), percentage error (PE), absolute percentage error (APE), mean percentage error (MPE), and mean absolute percentage error (MAPE) of the model simulations (Table 1), which are defined as follows:

$$
\begin{gathered}
\text { MBE }=\frac{1}{n} \sum_{i=1}^{n}\left(\mathrm{POAI}_{M}-\mathrm{POAI}_{S}\right) \\
\mathrm{MAE}=\frac{1}{n} \sum_{\mathrm{i}=1}^{\mathrm{n}}\left|\mathrm{POAI}_{\mathrm{M}}-\mathrm{POAI}_{\mathrm{S}}\right| \\
\mathrm{PE}=\frac{\sum_{\mathrm{i}=1}^{\mathrm{n}}\left(\mathrm{POAI}_{\mathrm{M}}-\mathrm{POAI}_{\mathrm{S}}\right)}{\sum_{\mathrm{i}=1}^{\mathrm{n}} \mathrm{POAI}_{\mathrm{S}}} \times 100 \% \\
\mathrm{APE}=\frac{\sum_{\mathrm{i}=1}^{\mathrm{n}}\left|\mathrm{POAI}_{\mathrm{M}}-\mathrm{POAI}_{\mathrm{S}}\right|}{\sum_{\mathrm{i}=1}^{\mathrm{n}} \mathrm{POAI}_{\mathrm{S}}} \times 100 \% \\
\mathrm{MPE}=\frac{1}{\mathrm{n}} \sum_{\mathrm{i}=1}^{\mathrm{n}} \frac{\mathrm{POAI}_{\mathrm{M}}-\mathrm{POAI}_{\mathrm{S}}}{\mathrm{POAI}_{\mathrm{S}}} \times 100 \% \\
\mathrm{MAPE}=\frac{1}{\mathrm{n}} \sum_{\mathrm{i}=1}^{\mathrm{n}}\left|\frac{\mathrm{POAI}_{\mathrm{M}}-\mathrm{POAI}_{\mathrm{S}}}{\mathrm{POAI}_{\mathrm{S}}}\right| \times 100 \%,
\end{gathered}
$$


where $\mathrm{n}$ is the total number of data points for all the wavelengths in 1 day, and the subscripts " $M$ " and " $\mathrm{S}$ " represent model simulation and surface observation, respectively. As shown in Table 1, FARMS-NIT has significantly smaller uncertainties than TMYSPEC for all the statistical measures in Table 1.
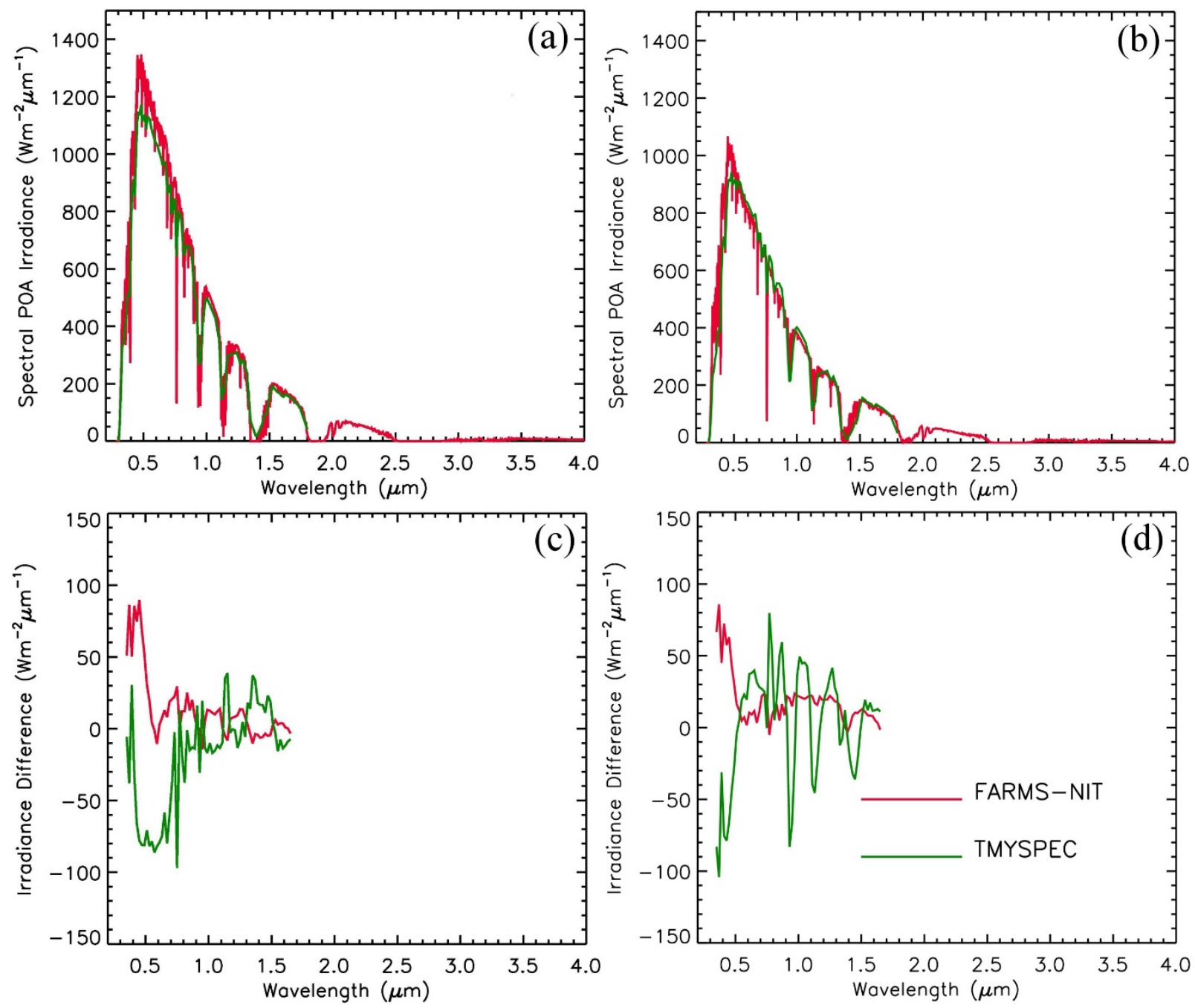

Figure 9. Comparison of spectral POA irradiances computed by FARMS-NIT and TMYSPEC (a) at 10:05 a.m. on October 20, 2017, and (b) 12:00 p.m. on January 22, 2018. Difference between model simulation and NREL observations on a single-axis tracker (c) at 10:05 a.m. on October 20, 2017, and (d) 12:00 p.m. on January 22, 2018 
Table 1. MBE, MAE, PE, APE, MPE, and MAPE of Computed Spectral Irradiances in the POA Using FARMS-NIT and TMYSPEC

\begin{tabular}{|c|c|c|c|c|c|c|}
\hline \multicolumn{7}{|c|}{ October 20, 2017} \\
\hline & $\operatorname{MBE}\left(\mathbf{W m}^{-2} \mu \mathrm{m}^{-1}\right)$ & $\operatorname{MAE}\left(\mathrm{Wm}^{-2} \mu \mathrm{m}^{-1}\right)$ & $\begin{array}{l}\text { PE } \\
(\%)\end{array}$ & APE (\%) & MPE (\%) & MAPE (\%) \\
\hline FARMS-NIT & 9.64 & 15.31 & 1.86 & 2.96 & -2.03 & 6.78 \\
\hline TMYSPEC & -17.96 & 30.29 & -3.47 & 5.85 & 20.32 & 27.4 \\
\hline \multicolumn{7}{|c|}{ January 22, 2018} \\
\hline & $\operatorname{MBE}\left(\mathrm{Wm}^{-2} \mu \mathrm{m}^{-1}\right)$ & $\operatorname{MAE}\left(\mathrm{Wm}^{-2} \mu \mathrm{m}^{-1}\right)$ & $\begin{array}{l}\text { PE } \\
(\%)\end{array}$ & APE (\%) & MPE (\%) & MAPE (\%) \\
\hline FARMS-NIT & 11.13 & 17.92 & 2.28 & 3.67 & 1.94 & 5.57 \\
\hline TMYSPEC & -79.47 & 90.96 & -16.27 & 18.62 & -17.66 & 22.47 \\
\hline
\end{tabular}

The discrete ordinates radiative transfer (DISORT) model (Stamnes et al. 1988) is based on a solution of the radiative transfer equation pioneered by Chandrasekhar (1950). By replacing the integral of the radiative transfer equation with Gaussian quadrature, solar radiances can be solved in all possible directions. DISORT has been extensively used to simulate satellite observations and understand solar and infrared radiation within the atmosphere (Hong et al. 2009; Xie 2010,150; Xie et al. 2006; Xie et al. 2012a). Similar to FARMS-NIT, DISORT directly computes POA irradiance from radiances and Eq. (2) without further approximation. With idealized input of atmospheric properties, the uncertainty of DISORT in computing radiance has been well understood and discussed in previous studies (Ding et al. 2009; Kotchenova et al. 2006). Thus, DISORT allows extending the validation to atmospheric conditions with large AOD that do not exist in our surface observations.

In the model validation using surface observations, aerosol loading around NREL's SRRL is extremely low because of the high altitude and clean air in Colorado (see Figure 5c and Figure 5d); however, this might not be applicable to other locations where surface observations are unavailable. To understand the performance of FARMS-NIT under different conditions, we apply the profile of the 1976 U.S. Standard Atmosphere to a 64-stream DISORT and FARMS-NIT to compute the POA irradiances on October 20, 2017. A homogenous layer of aerosol with AOD varying from $0.01-1.0$ is applied to the models. The irradiances are also computed by TMYSPEC using the broadband GHI from DISORT. Compared to DISORT, the visible peak of irradiance is slightly overestimated by FARMS-NIT (Figure 10). The visible peak is underestimated by TMYSPEC for a thin aerosol layer (Figure 10a), but it gradually begins to overestimate the peak as the aerosol loading increases (Figure 10d). For the near-infrared region, TMYSPEC underestimates irradiance, which is more significant at higher AOD; however, the performance of FARMS-NIT is not significantly affected by the variation of AOD.

With the same atmospheric properties and PV orientation as Figure 9, the MAPE of FARMS-NIT is stable at $2 \%-4 \%$ even though its MPE increases with AOD from 0 to $4 \%$ (Figure 11). The MPE and MAPE of TMYSPEC both increase with AOD; the latter can reach up to $12 \%$ when the AOD is 1.0 . 

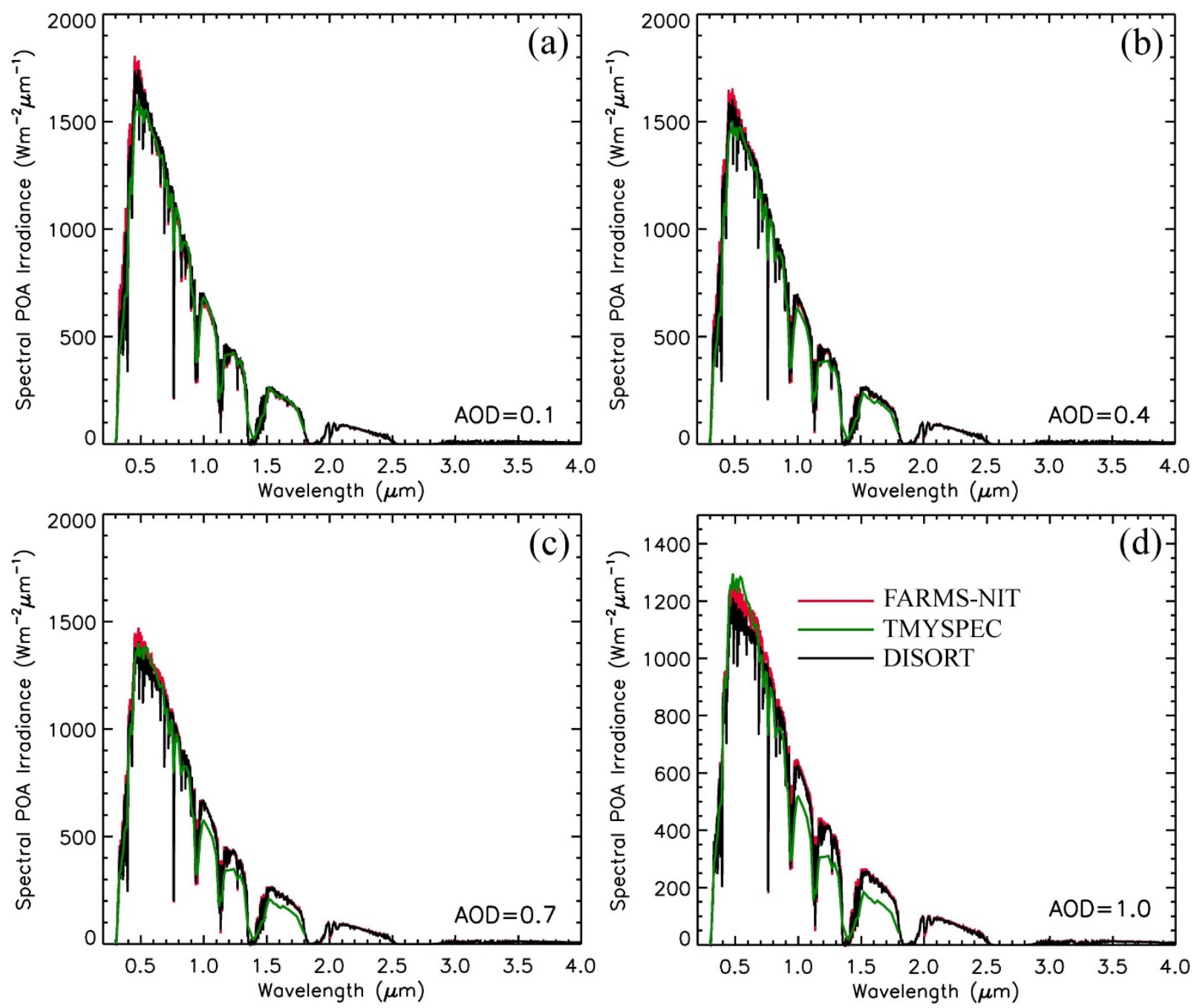

Figure 10. Comparison of spectral POA irradiances computed by FARMS-NIT, TMYSPEC, and DISORT at 12:00 p.m. on October 20,2017 , when the solar zenith angle is $50.447^{\circ}$. A PV panel is assumed facing south with a tilt angle of $30^{\circ}$.

For computing hourly spectral POA irradiances during a day, the 64-stream DISORT, 16-stream DISORT, FARMS-NIT, and TMYSPEC consume 650880.0 seconds (180 hours, 48 minutes), 11912.7 seconds (3 hours, 18 minutes, 32.7 seconds), 21.9 seconds, and 2.31 seconds, respectively (Figure 12) using a single Intel Xeon processor core the NREL's flagship high-performance computing system. Thus, FARMS-NIT increases the computational efficiency of the current radiative transfer models by a factor of greater than 500 compared with the 16-stream DISORT. Although FARMS-NIT requires more computational resources than TMYSPEC, it provides spectral irradiances in 2002 wavelength bands, whereas TMYSPEC has only 151 bands. 

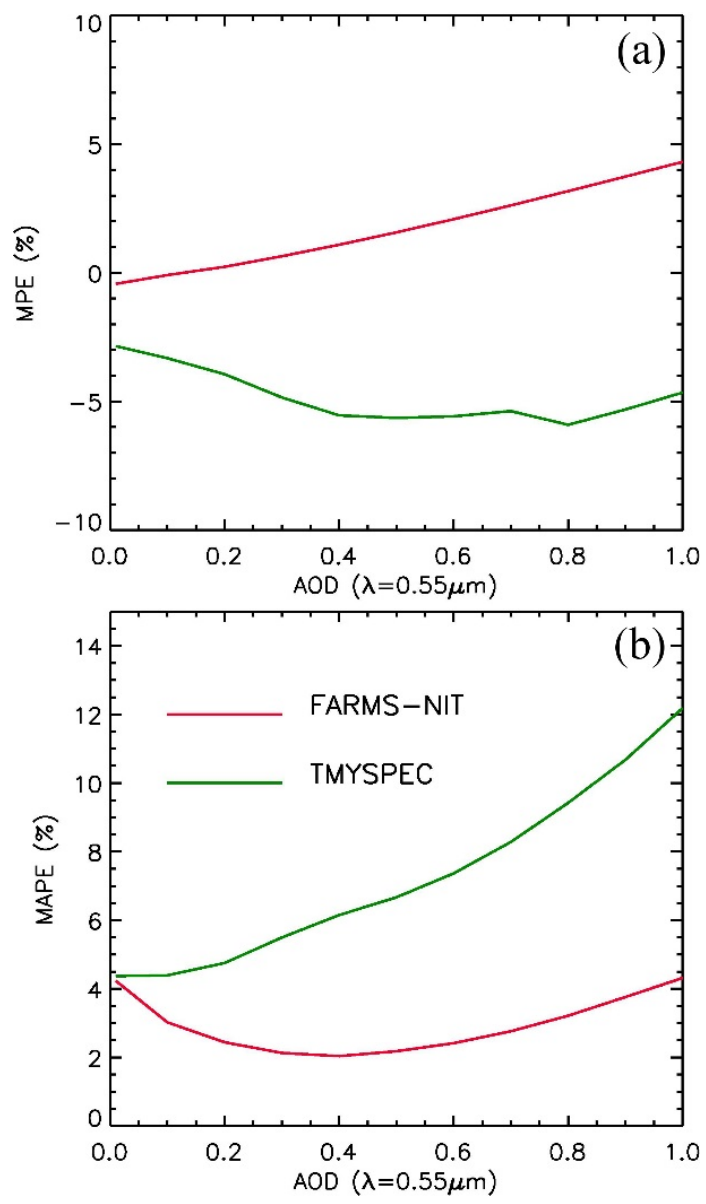

Figure 11. Comparison of spectral POA irradiances computed by FARMS-NIT, TMYSPEC, and DISORT at 12:00 p.m. on October 20,2017 , when the solar zenith angle is $50.447^{\circ}$. A PV panel is assumed facing south with a tilt angle of $30^{\circ}$.

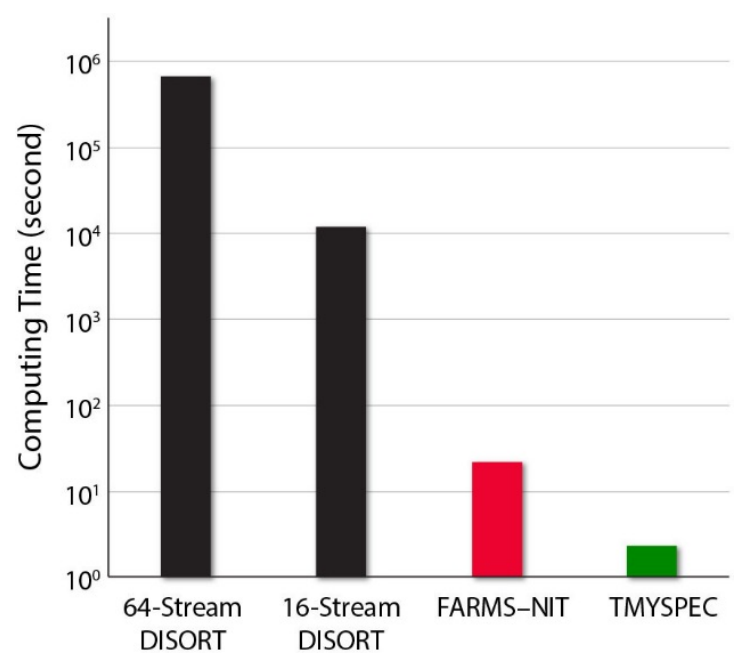

Figure 12. Computing time of hourly spectral POA irradiances during a day 


\subsection{A New Algorithm to Evaluate Transposition Models Using FARMS-NIT}

Although FARMS-NIT results in noticeable biases as a result of the measurement uncertainties in the atmospheric and land surface properties, its performance can be substantially improved by using idealized input data, which provides more reliable computations of GHI and POA irradiance. On the other hand, a highly accurate GHI estimate or measurement cannot reduce the systematic error and limitation inherent in the transposition models. These uncertainties and their sensitivities to the atmospheric and land surface properties can therefore be identified from experiments designed to compare them to FARMS-NIT.

Figure 13 illustrates the procedure for assessing the uncertainty of transposition models using FARMSNIT. Instead of using measurements, FARMS-NIT employs predetermined atmospheric properties, solar zenith and azimuth angles, and PV orientations to accurately compute GHI and POA irradiance. The latter is compared to transposition models that use GHI data computed by FARMS-NIT as input data.

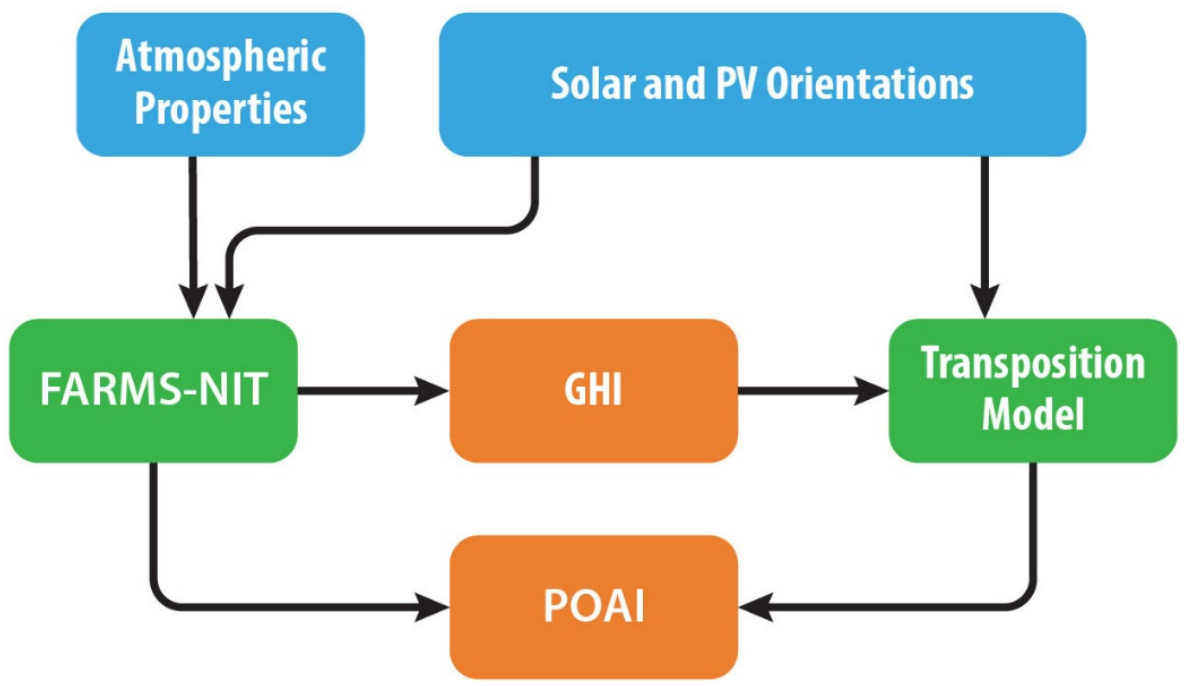

Figure 13. A flowchart of computing POA irradiances using FARMS-NIT and transposition models. The blue boxes denote input data, the green boxes denote models, and the orange boxes denote results.

We apply FARMS-NIT to an atmosphere following the 1976 U.S. Standard Atmosphere in which the amount of precipitable water vapor and carbon-dioxide columnar volumetric concentration are adjusted to $2 \mathrm{~cm}$ and $330 \mathrm{ppmv}$, respectively. We assume a Lambertian land surface with an albedo of 0.25 when the sun is in the south at a solar zenith angle of $30^{\circ}$; a monofacial PV panel faces south spanning a wide range of tilt angles from $0^{\circ}-90^{\circ}$. Figure 14 compares the POA irradiances computed by FARMS-NIT, LJ1963, BA2002, and PEREZ for clear- and cloudy-sky conditions. For the clear sky, we use the rural aerosol model (Shettle and Fenn 1979) by assuming an AOD of 0.5 in the wavelength of $0.5 \mu \mathrm{m}$. For the cloudy sky, we assume a plan-parallel layer of clouds composed of water droplets with an effective diameter of $10 \mu \mathrm{m}$. The cloud optical thicknesses are given as 3 and 10, representing relatively thin and thick clouds, respectively. For figures 6a through 6c, we compute DNI based on the Beer-BouguerLambert law (Liou 2002) using the optical thicknesses of the clouds and the clear atmosphere. For figures 6d through 6f, we decompose DNI using the DISC model (Maxwell 1987) and the computed GHI. We found that LJ1963 and BA2002 underestimate POA irradiances during the clear sky and the cloudy sky covered by a thin cloud when the forward scattering is stronger than that in other directions. The underestimation becomes less significant when DNI is computed by the DISC model, which 
accounts for some diffuse radiation around the forward direction. Thus, the DISC model used in conjunction with most transposition models provides better accuracy than the Beer-Bouguer-Lambert law. LJ1963 and BA2002 slightly overestimate the POA irradiance of thick clouds, especially for large PV tilt angles. It is also evident that PEREZ and FARMS-NIT compare extremely well under clear-sky conditions, both when DNI is computed using the Beer-Bouguer-Lambert law or DISC model; however, PEREZ provides more cloudy-sky POA irradiance than FARMS-NIT when the sun and PV panel are in the same azimuthal direction, as demonstrated by figures 14b, 14c, 14e, and 14f.
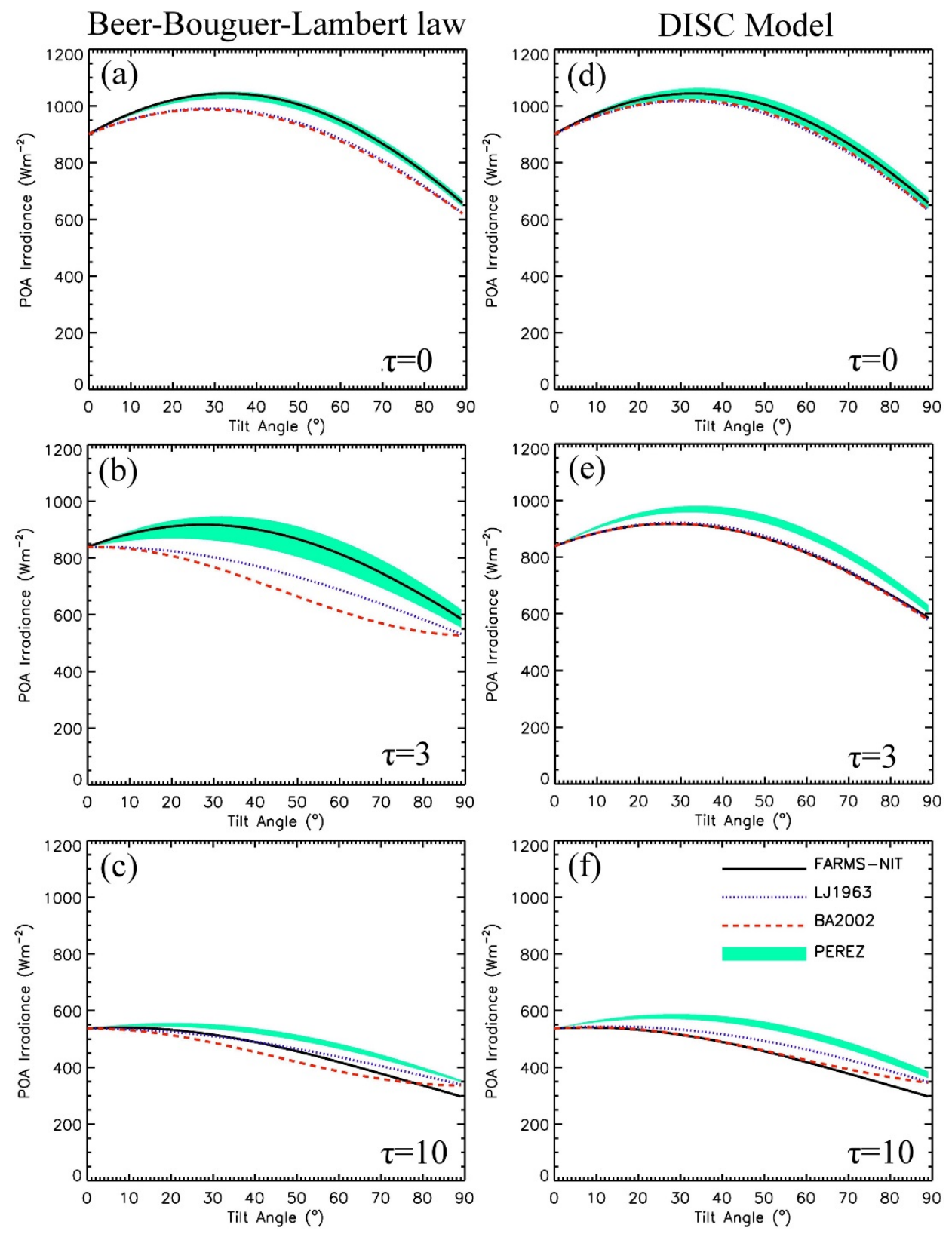

Figure 14. POA irradiances computed for (a) a clear-sky condition and cloudy-sky conditions with cloud optical thickness $\mathrm{T}$ of (b) 3 and (c) 10. The sun is in the south with a zenith angle of $30^{\circ}$. A PV panel is facing south with various tilt angles. The DNIs in $(a-c)$ are computed by the Beer-Bouguer-Lambert law. And (d-f) are the same as (a-c) except that DNI is computed using the DISC model. 

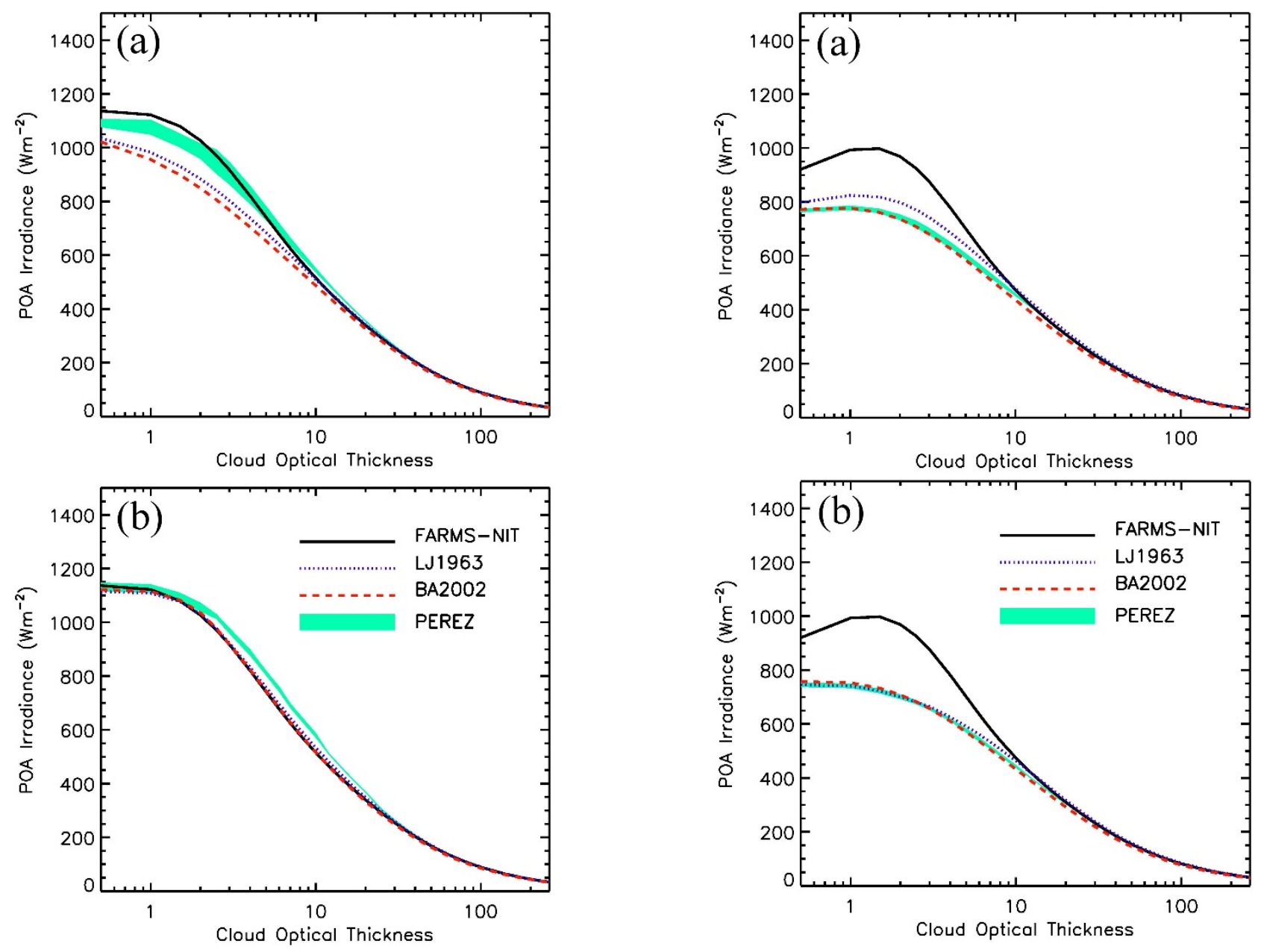

Figure 15. POA irradiances when the sun is in the south with a zenith angle of $30^{\circ}$. The PV panel faces south, and $\beta=30^{\circ}$. DNI is computed by the (a) Beer-Bouguer-Lambert law and (b)

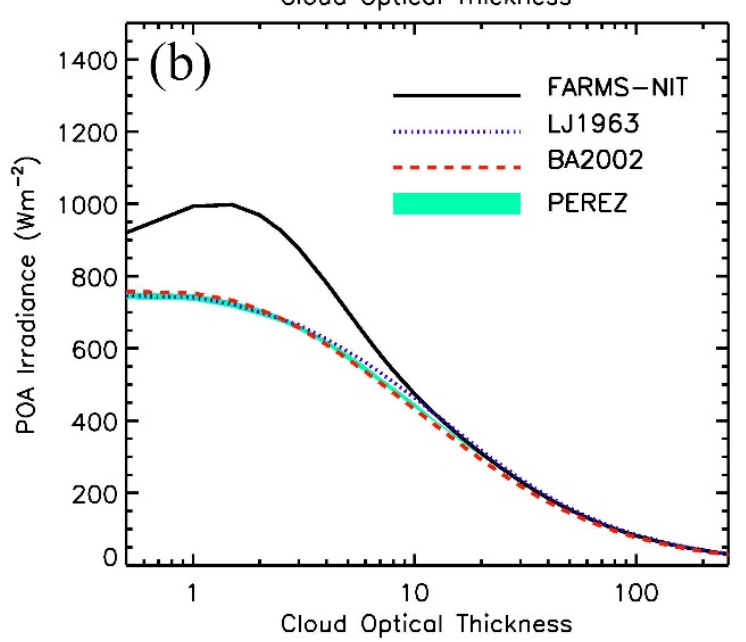

Figure 16. Same as Figure 15 except that the PV panel faces east, and $\beta=45^{\circ}$.

To further understand the impact of clouds on the transposition models, we investigate a variety of cloud optical thicknesses, from 0.5-300, when the direct solar radiation is perpendicular to a PV panel with a tilt angle of $30^{\circ}$. Figure 15 demonstrates that LJ1963 and BA2002 using the Beer-Bouguer-Lambert law underestimate POA irradiance, but they have an excellent agreement with FARMS-NIT when the DISC model is employed. Similar to Figure 14, PEREZ results in slightly larger cloudy-sky POA irradiances than FARMS-NIT, except for thin or very thick clouds.

Figure 16 is the same as Figure 15 except that the PV panel faces east with a tilt angle of $45^{\circ}$. It is evident that the transposition models might result in substantial differences compared with FARMS-NIT when the PV panel orientation deviates from the azimuthal direction of the sun, which is quite common for PV panels with fixed orientations. As shown, PEREZ is roughly in accordance with the isotropic models when the PV panel deviates $90^{\circ}$ from the solar azimuth angle. For most cloud conditions, the POA irradiances computed by the transposition models are significantly smaller than FARMS-NIT, which is probably a result of the underestimation of side scattering that still provides an important contribution to the POA irradiance. Thus, future validation studies are required to comprehensively 
understand model uncertainties as a function of the azimuth angle difference between the sun and PV panels.

\subsection{Data Dissemination}

The National Solar Radiation Data Base (NSRDB) Spectral Data On-Demand download tool provides users with access to the spectral solar radiation data via the NSRDB Viewer in an easy-to-use interface as well as via a download application programming interface. The viewer components provide access to a map tool for selecting the location as well as an input form for choosing the data year and download options. Options include calculating the spectral data for fixed and one-axis systems.

Once a request is submitted, a spectral data generation job is placed into a job queue. A dedicated highperformance server consumes jobs in the order received and generates the requested data as quickly as possible. As soon as the data have been generated and are available for download, a signal is sent back up the job queue, which triggers an email.

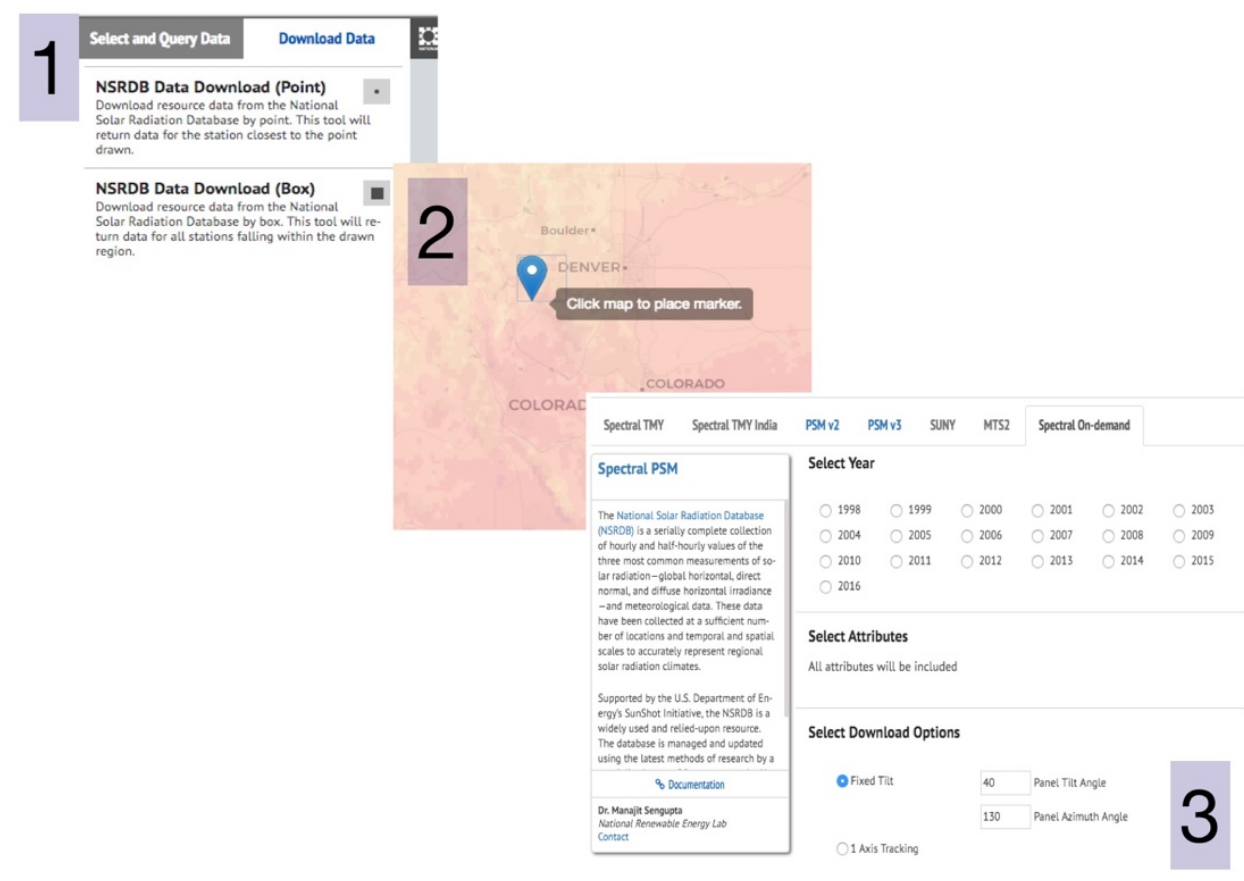

Figure 17. A diagram of the NSRDB Viewer

\subsection{Measurements}

\subsubsection{NREL SRRL Instrumentation Suite}

The instrumentation suite at NREL and the University of Oregon was chosen based on the need to have a "best" reference cell measurement as well as other irradiance measurements that are typical in the field and represent a mix of measurement options. We wanted to represent the common POAs in which the instruments might be used, including global horizontal, fixed tilt, one-axis, (and, later, two-axis). The instruments included reference cells, photodiodes, and thermopiles. Initially, we included a World PV Scale Standard (WPVS) reference cell. We chose the WPVS because it represented the "best" possible package regarding its manufacturing, temperature measurement, and measurement precision. We 
intended to install a WPVS reference cell in each of the different POAs; however, NREL purchasing requirements necessitated purchasing these through a third party. This, combined with the already high cost of the cells, caused our team to rethink including the WPVS. So we decided not to purchase the WPVS reference cells and instead used the reference cells more commonly used in the field. Note, however, that Keith Emery agreed to lend us two spare WPVS reference cells that could be used for the internal comparisons, and these were installed at NREL from March 3, 2016, to July 16, 2016 (4 months), before they had to be returned.

We chose one each of two common types of reference cells: split cells (the RCO) and single cells (the IMT). Reference cells (and any silicon sensor, for that matter) need to be corrected for temperature effects. These two types of refence cells determine their internal temperatures in different manners. One reference cell uses an internal thermistor, and the other (the split cell) determines the temperature from one of the two cells (open-circuit voltage) and irradiance from the other (short-circuited with a shunt). The IMT is likely the most commonly found reference cell in PV power operations. We also included one or more thermopiles and photodiodes. Initially, there was one thermopile (the CMP22 from Kipp \& Zonen), and later a second was added (the MS-80 from EKO). The final instrumentation list is shown in Figure 18.
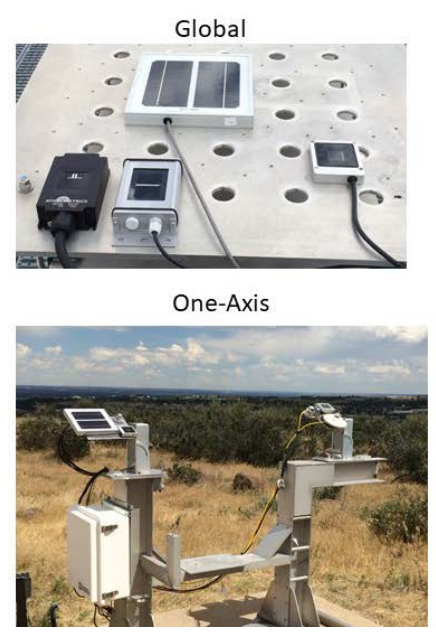

Figure 18. Instrumentation suite and POAs used in the SRRL PV resource study

In addition to the instrumentation suite, we needed to design a method for one-axis tracking that could support the weight of the instrumentation. The best option at the time given budget decreases for the project was to modify the Eppley LI-2020 tracker. The LI-2020 is designed to operate in a two-axis motion. We removed one of the motors and its axis so that it would rotate only in the zenith. After removing the motor and axis, we added a stepper motor control board to the system along with the necessary code operating the control board. Because of the weight of the instrumentation, we needed to modify two of these trackers to accommodate all the sensors. Figure 19 illustrates the LI-2020 two-axis tracker before and after the modification along with the control board that is used to run the stepper motor and the final configuration. 


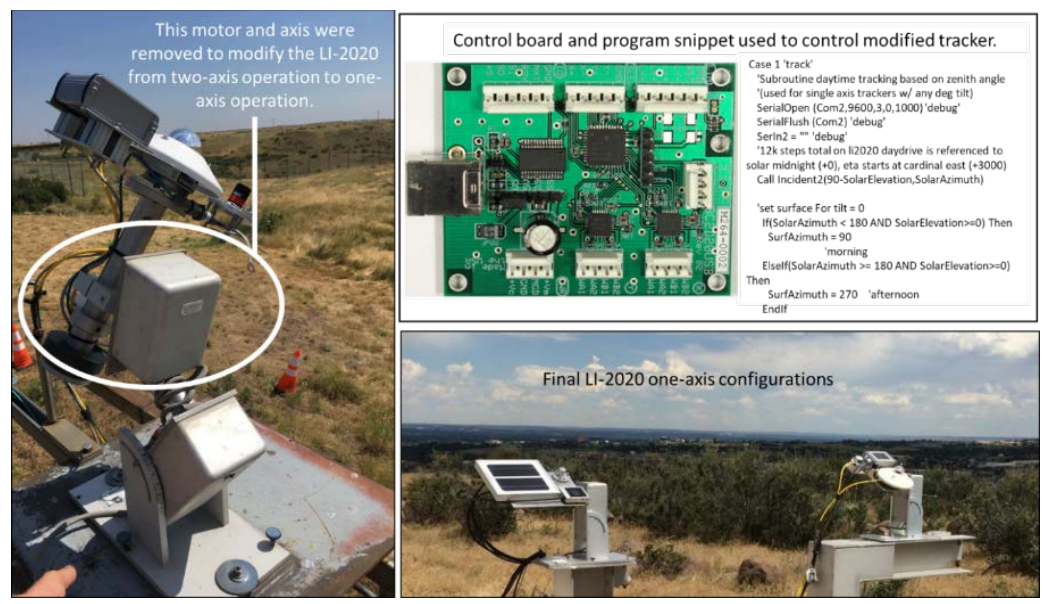

Figure 19. Modification of LI-2020 two axis-trackers to operate as a one-axis tracker

Initial studies indicated the need for understanding the effects of the changing spectrum on the different sensor types in the varying POAs. We installed a spectroradiometer in a one-axis POA. The options for an outdoor rated spectroradiometer that could operate on continuous basis were limited then (and now). At the time, the only options were the LI-1800 (of which we had a spare) and the EKO WISER, which consists of two spectroradiometers together measuring from $300-1600 \mathrm{~nm}$. This system is very robust and provides a good measurement but is also on the order of $\$ 60,000$ to purchase. Our only option was to go with the LI-1800, but we knew this would have downsides, including:

1. The LI-1800 has a huge dependence on temperature, and therefore it must be maintained at $40^{\circ} \mathrm{C}$. We were able to obtain a temperature controller from another group.

2. Even with the temperature controller, we knew we would not be able to maintain $40^{\circ} \mathrm{C}$ in the summer when it gets very hot. We added fans to the system, which helped, but there were still large periods of time during the summer when the temperature got too high during the day and the data were too uncertain to be used.

3. The spectral range is limited from 350-1000 $\mathrm{nm}$.

4. The LI-1800 has a large cosine dependency.

5. The LI-1800 is weather resistant but still prone to moisture infiltration.

6. Data collection takes place during a minute. During variable conditions, this leads to poor measurements because the conditions change during the 1 minute of data collection.

7. The calibration is not very stable.

8. The dome is plastic and easily damaged (e.g., it was damaged during a hailstorm).

9. The LI-1800 is heavy and has a cumbersome amount of cabling associated with it, which made it impractical to mount on the smaller LI-2020 tracker.

This was our only option at the time for spectral measurements, and we moved forward with it. Leading up to this, we realized the need for a spectral measurement and a means of carrying the heavier instrumentation in a one-axis motion, and we had been discussing the possibility of this with the various tracker manufacturers. The EKO STR-32G tracker turned out to be a great option for modifying to oneaxis tracking. The metrology group had a spare STR-32G tracker that we could use for most of the year, 
but it would need to be removed from service for a few months to serve their needs. We moved forward with this option and used the system pictured in Figure 20.

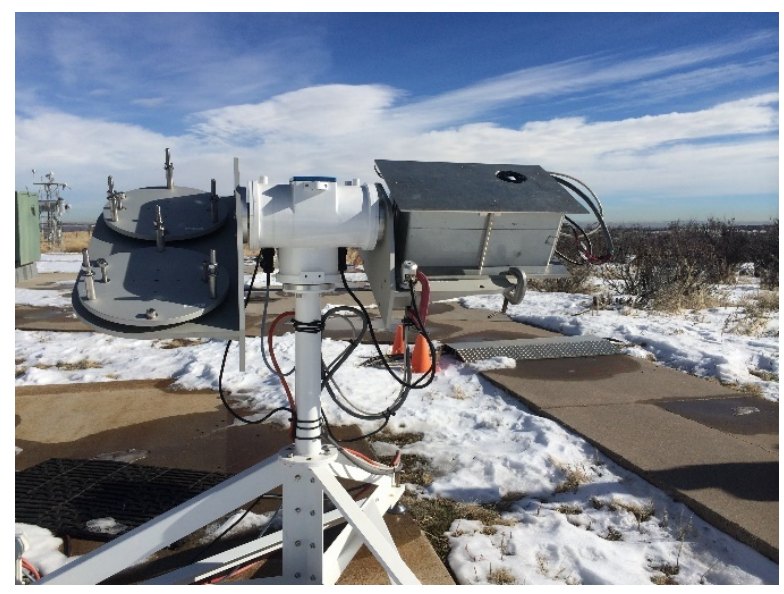

Figure 20. The EKO STR-32G tracker operating in a one-axis motion and carrying the LI-1800 spectroradiometer

On May 8, 2017, Denver experienced the worst hailstorm in the area's history. This hailstorm damaged many of our systems and instruments, including the LI-1800 spectroradiometer. Using some reserve funds, NREL provided money to replace and even upgrade some of these damaged systems. As a result, we were able to purchase an EKO STR-32G tracker along with an MS711/712 WISER combination. The new system had the following benefits and is pictured in Figure 21:

1. The range is increased from $350-1,650 \mathrm{~nm}$.

2. No external temperature control is required.

3. The calibration is more stable than the LI-1800.

4. The dome is glass and durable.

5. The weather resistance is excellent.

6. Data collection takes place within a second, which means that we can more accurately capture the resource during variable conditions.

7. The cosine response is good.

8. There are no moving parts.

9. Data collection is done via logger rather than PC, making the collection more reliable.

Regarding the evolution of our one-axis tracking system, the main disadvantage with the new one-axis tracking system using the modified LI-2020 tracker was that the thermopiles, photodiodes, and reference cells were on two separate (and less reliable) trackers and the spectroradiometers were on the more robust STR-32G. This meant that the POA could be off by a couple of degrees for any of the three trackers and would be very difficult to notice. We decided to move all the sensors to the one STR-32G tracker, thus ensuring that all sensors would always be in the same POA. Figure 21 illustrates this new system. We developed a means of controlling the tracker such that we could put it into a one-axis tracking mode, we could put it in horizontal mode for calibration purposes, we could run through a full day in a couple of minutes to demonstrate the one-axis motion, or we had the option of putting it into 
any zenith and elevation needed. We parked the tracker at night in a horizontal position so that it is less affected by the high winds sometimes experienced at the SRRL during nighttime.

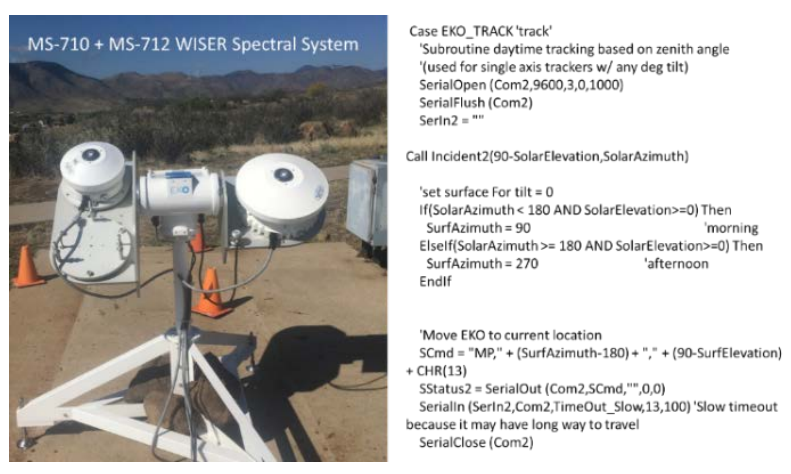

Figure 21. EKO STR-32G tracker modified to operate in one-axis tracking mode with WISER spectral system along with snippet of code used to control the STR-32G

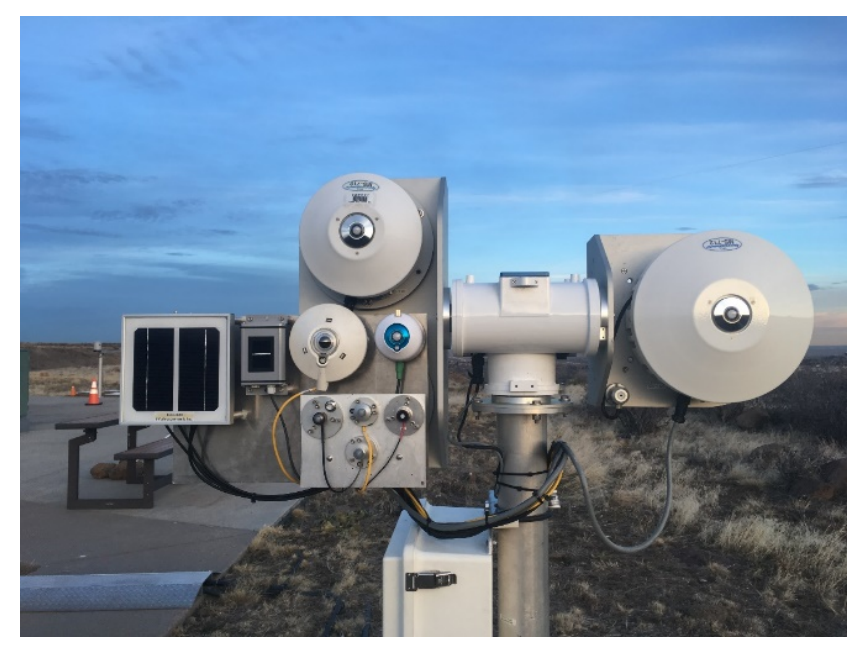

Figure 22. STR-32G, modified to operate as a one-axis tracker with the WISER spectral system, two thermopiles, two reference cells, and four photodiodes

\subsubsection{University of Oregon}

One of our partners is the University of Oregon, which operates and maintains the Solar Radiation Monitoring Laboratory. We chose this location because the university already maintains radiometers and is familiar with the proper procedures for doing so. In addition, the location offers a different climatic regime than Golden, Colorado, where the SRRL is located, and the University of Oregon has calibration capabilities which that were needed because of the long turnover time that would be required to get the sensors calibrated at the SRRL and returned to the university. (Our budget did not allow for a full set of spares, which could have mitigated this issue.) The final configuration of sensors in shown in Figure 23.

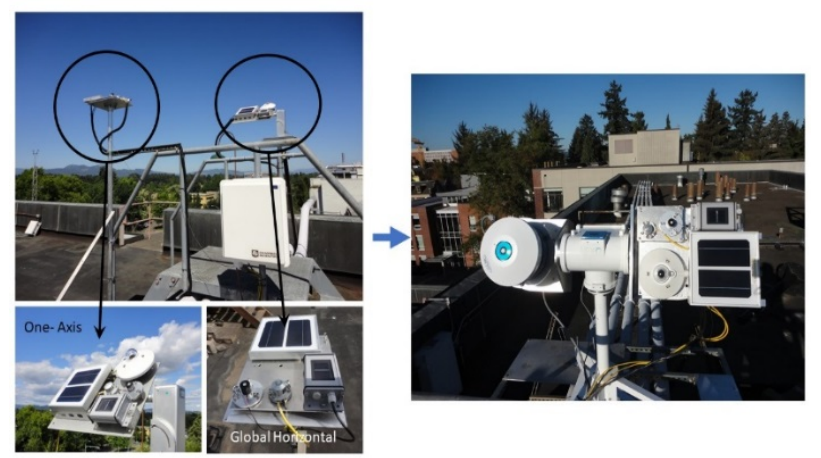

Figure 23. Instrument configuration at the University of Oregon's Solar Radiation Monitoring Laboratory

NREL included funds in the subcontract for the University of Oregon to maintain the calibration of their absolute cavity through the NREL Pyrheliometer Comparison. Representatives from the university have attended three NREL Pyrheliometer Comparison events to maintain the traceability of their cavity. 
The University of Oregon one-axis tracking system and the spectral measurement capacity followed the same evolution as that of the SRRL system as described in Section X. Initially, there was a single LI2020 tracker that had a thermopile, two photodiodes, and two reference cells. In August 2018, we replaced this system with a STR-32G tracker and added the EKO MS-711 spectral measurement, which was not a part of the original sensor suite. (Figure 6 shows the old and new arrangement.) We plan to leave this unique set of measurements installed at the University of Oregon for another period (from 1-3 years, depending on funding).

\subsubsection{First Solar}

As a result of reduced funding, we could not partner with as many entities as we initially intended to and thus needed devise other means of obtaining meaningful data. We partnered with First Solar, which has multiple plants around the world that have POA reference modules alongside POA thermopiles and global horizontal thermopiles. We started with five stations with 1-3 years of data. Currently, we have seven stations, two of which have two configurations within them. The stations consist of different technologies and different tracking POAs. The stations are listed in Figure 24, and notes regarding each of the stations are listed in Table 2.

Table 2. Solar Monitoring Station Data from First Solar

\begin{tabular}{|c|c|c|c|c|c|c|c|c|}
\hline Site \# & POA type & Azimuth & Technology & $\begin{array}{c}\text { Time } \\
\text { Zone }\end{array}$ & Altittude & Start & End & Location \\
\hline Site 1 & Tracker & 180 & csi & -7 & 617.7 & $1 / 1 / 2013$ & $12 / 31 / 2017$ & Arizona 40 miles NW of Tucson \\
\hline Site 2 (Tracker) & Tracker & 180 & csi & -8 & 818.3 & $7 / 1 / 2014$ & $12 / 31 / 2017$ & Southern California 60 miles north of LA (Neenach, CA) \\
\hline Site 2 (Fixed Tilt) & Fixed (25) & 180 & csi & -8 & 818.3 & $2 / 1 / 2013$ & $12 / 31 / 2017$ & Southern California 60 miles north of LA (Neenach, CA) \\
\hline Site 3 & Tracker & 180 & csi & -7 & 1446 & $6 / 1 / 2014$ & $12 / 31 / 2017$ & Southwestern New Mexico 70 miles west of white sands \\
\hline Site 4 & Tracker & 180 & csi & -8 & -40.5 & $12 / 1 / 2014$ & $12 / 31 / 2017$ & Salton Sea 40 miles South of Palm Springs \\
\hline Site 4 & Tracker & 180 & cdte & -8 & -40.5 & $12 / 1 / 2014$ & $12 / 31 / 2017$ & Salton Sea 40 miles South of Palm Springs \\
\hline Site 5 & Fixed (20) & 0 & csi & +8 & 201 & $9 / 21 / 2012$ & $12 / 31 / 2017$ & Western Australia \\
\hline Site 6 & Fixed (20) & 180 & csi & +4 & 113 & $11 / 1 / 2013$ & $12 / 31 / 2017$ & Dubai \\
\hline Site 7 & Fixed (25) & 180 & csi & -5 & 267 & $2 / 1 / 2013$ & $12 / 31 / 2017$ & South Lake Huron Canada \\
\hline
\end{tabular}

\subsubsection{DeSoto PV Plant, Arcadia, Florida}

Again, because of budget reductions, we sought a previous partner with whom we still had a cooperative research-and-development agreement that we could extend to accommodate a set of measurements at the site. Unlike the University of Oregon, these sensors would not get a regular cleaning because the site personnel were busy with developing an additional $75 \mathrm{MW}$ of fixed-tilt panels. That said, the location would represent another type of geography and could be installed in a 2-day trip. One sensor failed in the field (LI-200 photodiode). We also saw evidence of heavy dust; however, afternoon rain showers helped mitigate this issue. The resulting sensor configuration consisted of one thermopile, two photodiodes, and two reference cells in the POA as well as one thermopile and one photodiode in the GHI, as shown in Figure 24. The Desoto system was removed in mid-September per the subcontract agreement. 


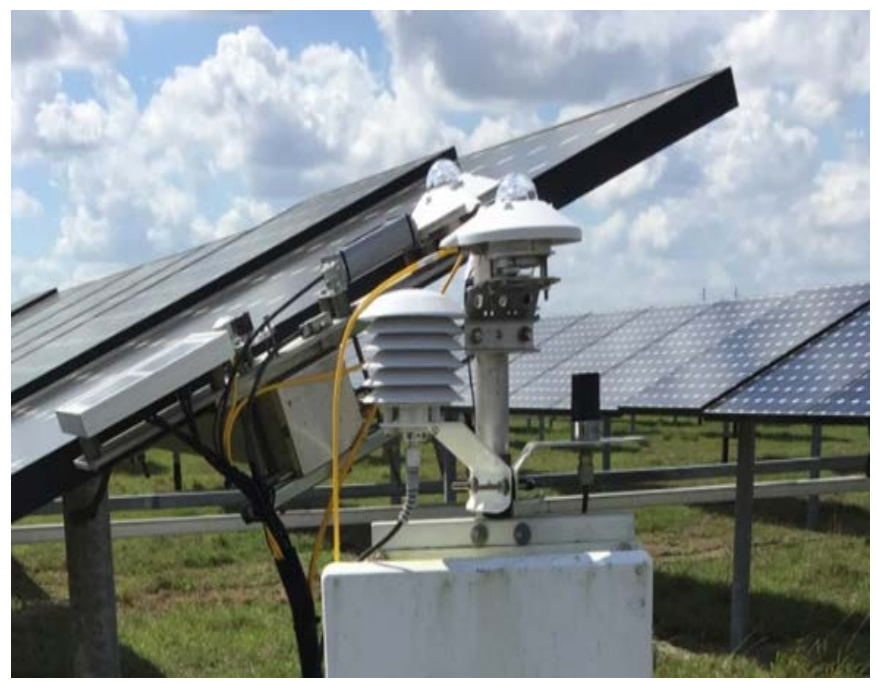

Figure 24. Test setup at Desoto PV plant in Arcadia, Florida. The system included a thermopile, reference cell, and photodiode in the one-axis POA and a thermopile and photodiode in the GHI orientation.

\subsubsection{Data Collection}

Data were collected via radio and/or through the Internet. The data for all the SRRL configurations and the University of Oregon configuration are posted on the Measurement and Instrumentation Data Center and can be found at https://midcdmz.nrel.gov/pv resource/. Station comparisons can be done as shown in Figure 25. Desoto data are obtained from a password-protected site. The First Solar spectral data are not on the Measurement and Instrumentation Data Center site.

\begin{tabular}{|c|c|c|c|c|c|c|c|}
\hline \multicolumn{8}{|c|}{ Current Irradiance and Meteorological Conditions } \\
\hline \multicolumn{4}{|c|}{ - Entire Day (0:00-24:00 LST) } & \multicolumn{4}{|l|}{ Daytime (4:00-20:00 LST) } \\
\hline \multirow{2}{*}{\multicolumn{2}{|c|}{$\begin{array}{c}\text { PVResource GH } \\
\text { July 17, } 2018 \\
\text { 10:18 MST }\end{array}$}} & \multirow{2}{*}{\multicolumn{2}{|c|}{$\begin{array}{c}\text { PVResource SA } \\
\text { July 17, 2018 } \\
10: 55 \text { MST }\end{array}$}} & \multirow{2}{*}{\multicolumn{2}{|c|}{$\begin{array}{c}- \text { PVResource FT } \\
\text { July 17, } 2018 \\
\text { 10:08 MST }\end{array}$}} & \multirow{2}{*}{\multicolumn{2}{|c|}{$\begin{array}{c}-\underline{\text { SRRL BMS }}- \\
\text { July 17, 2018 } \\
10: 57 \text { MST }\end{array}$}} \\
\hline & & & & & & & \\
\hline Global Horiz WPVS & $-7999.00{\mathrm{~W} / \mathrm{m}^{2}}^{2}$ & Global 1-Axis MS-80 & $1045.76 \mathrm{~W}^{2}{ }^{2}$ & Global Tilt CMP22 & $868.12 \mathrm{~W}^{2}$ & Global CMP22(vent corr). & $970.17 \mathrm{~W}^{2}$ \\
\hline Global Horiz RCO & $873.24 \mathrm{Wm}^{2}$ & Global 1-Axis CMP22/CM21 & $1048.20 \mathrm{Wm}^{2}$ & Global Tilt LI-200 & $871.80{\mathrm{~W} / \mathrm{m}^{2}}^{2}$ & Global CMP22-1 (corr) & $964.84 \mathrm{Wm}^{2}$ \\
\hline Global Horiz RCO-TK & $871.99 \mathrm{Wm}^{2}$ & Global 1-Axis LI-200 & $1031.54 \mathrm{Wm}^{2}$ & Global Tilt SP-Lite2 & $855.50 \mathrm{Wm}^{2}$ & Global CMP22-2 (corr) & $966.46 \mathrm{Wm}^{2}$ \\
\hline Global Horiz IMT & $866.36 \mathrm{Wm}^{2}$ & Global 1-Axis SP-110 & $1057.17 \mathrm{Wm}^{2}$ & Global Tilt RCO & $867.09 \mathrm{~W}^{2}$ & Global CMP11 (corr). & $968.50 \mathrm{Wm}^{2}$ \\
\hline Global Horiz Aton & $864.39 \mathrm{Wm}^{2}$ & Global 1-Axis SP-Lite2 & $1031.87 \mathrm{Wm}^{2}$ & Global Tilt RCO-TK & $864.44{\mathrm{~W} / \mathrm{m}^{2}}^{2}$ & Global CM6b(corr) & $973.68{\mathrm{~W} / \mathrm{m}^{2}}^{2}$ \\
\hline Global Horiz WPVS (uncorrected) & $\quad 0.00{\mathrm{w} / \mathrm{m}^{2}}^{2}$ & Global 1-Axis ML-01 & $1072.85{\mathrm{~W} / \mathrm{m}^{2}}^{2}$ & Global Tilt IMT & $857.99{\mathrm{~W} / \mathrm{m}^{2}}^{2}$ & Global CM3 (corr) & $977.29 \mathrm{Wm}^{2}$ \\
\hline Global Horiz RCO (uncorrected) & $883.25{\mathrm{~W} / \mathrm{m}^{2}}$ & Global 1-Axis WPVS & $-7999.00{\mathrm{~W} / \mathrm{m}^{2}}^{2}$ & Global Tilt RCO (uncorrected & d) $874.53{\mathrm{~W} / \mathrm{m}^{2}}^{2}$ & Global SR25(corr) & $959.12 \mathrm{~W}^{2}$ \\
\hline Global Horiz IMT (mcorrected) & $874.73 \mathrm{Wm}^{2}$ & Global 1-Axis RCO & $1031.37{\mathrm{~W} / \mathrm{m}^{2}}^{2}$ & Global Tilt IMT (uncorrected) & $866.80{\mathrm{~W} / \mathrm{m}^{2}}^{2}$ & Global MS-80 & $956.00{\mathrm{~W} / \mathrm{m}^{2}}^{2}$ \\
\hline Global Horiz Aton (uncorrected) & $872.90 \mathrm{Wm}^{2}$ & Global 1-Axis RCO-TK & $1030.73{\mathrm{~W} / \mathrm{m}^{2}}^{2}$ & Global Tilt CMP22 & $8.29 \mathrm{mV}$ & Global MS-802 (cort). & $967.90 \mathrm{Wm}^{2}$ \\
\hline Global Horiz WPVS & $0.00 \mathrm{mV}$ & Global 1-Axis IMT & $1024.67{\mathrm{~W} / \mathrm{m}^{2}}^{2}$ & Global Tilt LI-200 & $4.21 \mathrm{mV}$ & Global MS-410 (corr). & $978.60{\mathrm{~W} / \mathrm{m}^{2}}^{2}$ \\
\hline Global Horiz RCO & $20.64 \mathrm{mV}$ & Global 1-Axis WPVS (uncorrected) & $-0.01 \mathrm{Wm}^{2}$ & Global Tilt SP-Lite2 & $54.40 \mathrm{mV}$ & Global MS-602 (corr) & $986.81 \mathrm{~W}^{2}$ \\
\hline Global Horiz RCO-Voc & $581.16 \mathrm{mV}$ & Global 1-Axis RCO (uncorrected) & $1039.47 \mathrm{Wm}^{2}$ & Global Tilt RCO & $82.69 \mathrm{mV}$ & Global SPP (vent corr) & $970.59 \mathrm{Wm}^{2}$ \\
\hline Global Horiz IMT & $51.17 \mathrm{mV}$ & Global 1-Axis IMT (uncorrected). & $1036.44 \mathrm{Wm}^{2}$ & Global Tilt RCO-Voc & $583.53 \mathrm{mV}$ & Global PSP(vent corr). & $965.30 \mathrm{Wm}^{2}$ \\
\hline Global Horiz Aton & $12.05 \mathrm{mV}$ & Global 1-Axis MS-80 & $10.58 \mathrm{mV}$ & Global Tilt IMT & $49.58 \mathrm{mV}$ & Global GPP (corr) & $963.12 \mathrm{Wm}^{2}$ \\
\hline WPVS Horiz Temp & $-7999.00{ }^{\circ} \mathrm{C}$ & Global 1-Axis CM-21 & $10.18 \mathrm{mV}$ & $\underline{\mathrm{RCO} \text { Tilt Temp }}$ & $53.58{ }^{\circ} \mathrm{C}$ & Global SP510 (corr) & $968.00 \mathrm{Wm}^{2}$ \\
\hline RCO Horiz Temp & $53.90^{\circ} \mathrm{C}$ & Global 1-Axis LI-200 & $4.90 \mathrm{mV}$ & RCO-TK Tilt Temp & $51.52{ }^{\circ} \mathrm{C}$ & Global TSP-700 (vent). & $951.99 \mathrm{Wm}^{2}$ \\
\hline RCO-TK Horiz Temp & $51.67{ }^{\circ} \mathrm{C}$ & Global 1-Axis SP-110 & $201.40 \mathrm{mV}$ & IMT Tilt Temp & $48.49^{\circ} \mathrm{C}$ & Global SP Lite2 & $944.89{\mathrm{~W} / \mathrm{m}^{2}}^{2}$ \\
\hline IMT Horiz Temp & $45.82^{\circ} \mathrm{C}$ & Global 1-Axis SP-Lite2 & $72.94 \mathrm{mV}$ & Logger Temp & $25.52{ }^{\circ} \mathrm{C}$ & Global ML-01 & $972.20 \mathrm{Wm}^{2}$ \\
\hline Aton Horiz Temp & $43.67{ }^{\circ} \mathrm{C}$ & Global 1-Axis ML-01 & $45.16 \mathrm{mV}$ & Logger Battery. & $14.05 \mathrm{VDC}$ & Global LI-200R & $950.64{\mathrm{~W} / \mathrm{m}^{2}}^{2}$ \\
\hline Logger Temp & $23.64^{\circ} \mathrm{C}$ & Global 1-Axis WPVS & $-0.00 \mathrm{mV}$ & Zenith Angle & 31.51 。 & Global LI-200 & $973.23{\mathrm{~W} / \mathrm{m}^{2}}^{2}$ \\
\hline Logger Battery. & $13.38 \mathrm{VDC}$ & Global 1-Axis RCO & $97.43 \mathrm{mV}$ & & & Global SP-110 & $963.99{\mathrm{~W} / \mathrm{m}^{2}}^{2}$ \\
\hline Zenith Angle & $29.83 \circ$ & Global 1-Axis RCO-Voc & $597.63 \mathrm{mV}$ & & & Global Research 1 & $987.27 \mathrm{~W} / \mathrm{m}^{2}$ \\
\hline & & Global 1-Axis IMT & $58.97 \mathrm{mV}$ & & & Global SAMPA Bird (calc). & $962.74{\mathrm{~W} / \mathrm{m}^{2}}^{2}$ \\
\hline
\end{tabular}

Figure 25. Data can be compared between any of the three configurations at the SRRL (fixed tilt, global, one-axis) as well as with the University of Oregon (one-axis and GHI configurations).

\subsubsection{Analysis}

Following is a summary of some of the findings in the analysis: 
1. Photodiodes experience an increased responsivity to the spectral shift that occurs in the morning and evening hours. This is enhanced with the one-axis tracking system, which looks directly east in the morning and west in the evening and thus "sees" a spectrum shifted toward the blue during those times because of the higher air mass.

2. Photodiodes are less affected by angle-of-incidence effects than reference cells because of their diffuser dome.

3. The refence cells have a flat glass plate and are heavily affected by the angle of incidence in the global position at zeniths as low as $55^{\circ}$, as shown in Figure 27 and Figure 28.

4. On a fixed-tilt or one-axis tracking surface, the angles of incidence are typically reduced, and photodiode-based pyranometers exhibit little angle-of-incidence effects but are more largely affected by spectral shifts that occur in the early morning, late afternoons, and even generally in the winter. (This is all because of increased air mass and the resultant shift to blue light that occurs).

5. With fixed-tilt configurations, there are times of the year when the sun rises and sets north of the east-west line. This results in very little to no direct beam on the instruments when the sun is north of the sensors, and thus there is a reduced angle-of-incidence effect.

6. There is a $\pm 10 \%$ at a $95 \%$ confidence interval for solar zenith angles up to $50^{\circ}$ compared to the reference thermopile-based pyranometer, which exhibits minimal thermal offset. Much of this deviance from the reference pyranometer comes during cloudy or partly cloudy periods.

7. For larger solar zenith angles, the reference cell measurements systematically differ from the reference pyranometers with transmission losses through the glazing most likely causing most of the decreased response. This difference between the reference cell and a reference pyranometer can reach $40 \%$.

8. Refence cells are more sensitive to long wavelengths (morning and evening hours); for reference cells, this increase in responsivity counters the effect of the reduction in the transmission of light through the glazing, and it results in better agreement with the thermopile than the photodiode does. The two affects cancel each other out to a certain degree.

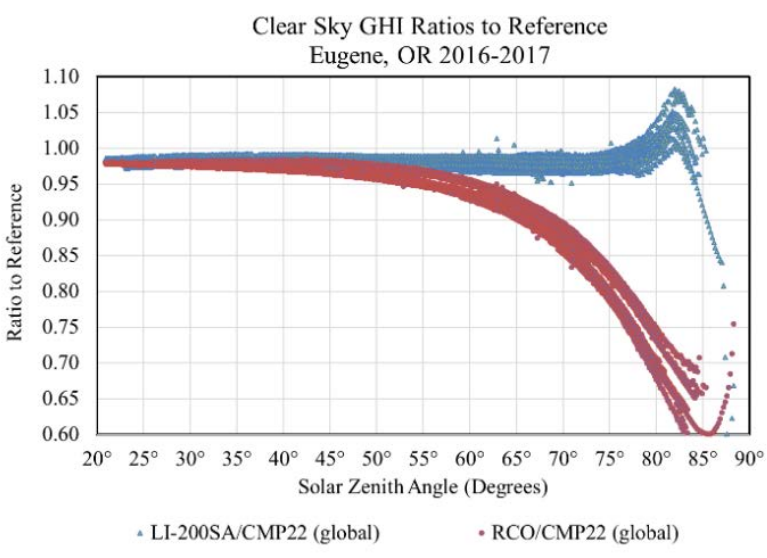

Figure 26. Ratios of GHI measurements to reference measurement on selected clear periods during the year in Eugene, Oregon

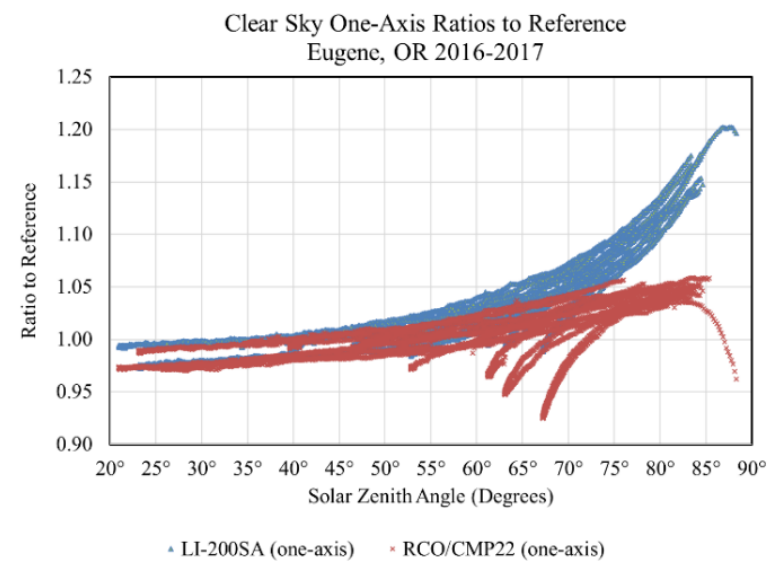

Figure 27. Comparison of the LI-200SA pyranometer and the RCO reference cell with the output of a CMP22 pyranometer 


\section{Conclusions and Future Work}

An efficient radiative transfer model, FARMS-NIT, was developed by parameterizing the transmission caused by multiple-scattering in the UV and visible regions and further simplifying the numerical integrations. The performance of FARMS-NIT is validated against surface observations at NREL's SRRL, spectral models for solar energy applications, and a physics-based radiative transfer model that is often used to simulate satellite observations. Our results show that the uncertainty of FARMS-NIT is within $5 \%$.

Note that the cloudy-sky computation in this study is made under the assumption of a plane-parallel cloud layer with a 1-D structure. Further studies are needed to understand the impact of cloud overlap effects and 3-D cloud effects on the simulation of POA irradiance. We also assume Lambertian surfaces in FARMS-NIT as a first-order approximation, whereas surface BRDF is important in computing POA irradiance (Dragsted 2011, 162; Xie et al. 2006), especially under snow conditions. Therefore, further enhancements of FARMS-NIT that include BRDF in snow and other surfaces are desirable and will improve the model accuracy though a corresponding improvement in the frequency, resolution, and availability of surface BRDF data, which will also be needed. Note that this study does not provide a complete validation for all possible time, location, and atmospheric conditions. The validation has been performed using only FARMS-NIT for selected atmospheric conditions and solar and PV panel orientations. Thus, future studies are desired to more comprehensively understand the differences between the models and offer recommendations for improvement. 


\section{Path Forward}

The spectral solar radiation data in the POA has been disseminated by the NSRDB website. We will maintain the data delivery, check data errors for specific cases, and answer users' questions. We will implement the knowledge we have gained from developing FARMS-NIT to develop a broadband FARMS-POA model and evaluate its accuracy using data collected at the NREL's SRRL. The developed and tested model can be used to enhance solar resource data sets such as the NSRDB and provide POA data with significantly improved accuracy than is currently available. Ultimately, the deployment of this model for developing POA time series and custom typical meteorological year data meeting specific solar deployments will significantly reduce the cost of solar deployments and improve the accuracy of integrating distributed solar on the electric grid.

The equipment acquired and used for this PV resource study and the subsequent measurements that are being taken are a unique and useful set of measurements to the research community. Our goal is to leverage this equipment and these measurements into our core work, through which we provide data, consultation, and calibration services. We also hope to secure the funds necessary to leave our equipment at the University of Oregon for an extended period of time so that we may acquire more data from that site, which is geographically and metrologically different than Golden, Colorado. The system at the University of Oregon will also be designed so that it is deployable to other locations with little setup time. To this end, we developed a plan to improve and make permanent these measurement systems. Following are the steps we intend to take:

1. We identified an issue with the rotation of the modified one-axis tracker. Although the system was designed with the manufacturer's input, it is being operated in a manner not consistent with its original design. The method that we employed involved a necessary azimuthal rotation at midday. During this rotation, the sky that the sensors see is reversed, and any small discrepancies in the level and the azimuthal response become apparent. We have worked with the manufacturer further to get a new board for the tracker that allows for unlimited rotation. This will allow us to rotate smoothly from east to west in the one-axis orientation without the midday rotation that caused a discontinuity in the data. We tested the new board and deployed it at the University of Oregon. We have not implemented it yet at the SRRL because it requires us to change some of the routing of the wiring and the direction of the mounting for the sensors. We have a plan for doing this and will implement it by the end of the fiscal year.

2. Our systems have developed over time and now consist of spectral measurements in the POA, and we are in the process of setting up a global normal station with spectral data so that we can better understand the spectral impacts at varying POAs by eliminating or greatly reducing the AOI effects. 


\section{Publications from This Work}

\section{Journal Publications}

Xie, Y., Sengupta, M., Dooraghi, M. 2018. "Assessment of Uncertainty in the Numerical Simulation of Solar Irradiance Over Inclined PV Panels: New Algorithms Using Measurements and Modeling Tools." Solar Energy 165: 55-64.

Xie, Y., and M. Sengupta. 2018. "A Fast All-sky Radiation Model for Solar Applications with Narrowband Irradiances on Tilted surfaces (FARMS-NIT): Part I. The Clear-Sky Model.” Solar Energy 174C: 691-702.

Xie, Y., M. Sengupta, and C. Wang. In preparation. "A Fast All-sky Radiation Model for Solar Applications with Narrowband Irradiances on Tilted surfaces (FARMS-NIT): Part II. The Cloudy-Sky Model." Solar Energy.

Gueymard, C. In preparation. "Surface Albedo for Solar Irradiance Modeling: Definitions, Data Sources, and Validation in Support of the National Solar Radiation Database (NSRDB)." Solar Energy.

\section{Conference and NREL Publications}

Xie, Y., and M. Sengupta. 2016. "Diagnosing Model Errors in Simulations of Solar Radiation on Inclined Surfaces." Presented at the IEEE Photovoltaic Specialists Conference (PVSC), Portland, Oregon, June 5-10, 2016.

Xie, Y., and M. Sengupta. 2016. "Performance Analysis of Transposition Models Simulating Solar Radiation on Inclined Surfaces." Presented at the European PV Solar Conference and Exhibition (EU PVSEC), Munich, Germany, June 20-24, 2016.

Maclaurin, G., M. Sengupta, and Y. Xie. 2017. Development of MODIS-Derived Surface Albedo: Enhanced Model Input to the NSRDB (Technical Report NREL/TP-6A20-67306). Golden, CO: National Renewable Energy Laboratory, 2017.

Xie, Y., M. Sengupta, and C. Deline. 2017. "Recent Advancements in the Numerical Simulation of Surface Irradiance for Solar Energy Applications.” Presented at the IEEE Photovoltaic Specialists Conference (PVSC), Washington, D.C, June 25-30, 2017.

Vignola, F., C. Chiu, J. Peterson, M. Dooraghi, and M. Sengupta. 2017. "Comparison and Analysis of Instruments Measuring Plane of Array Irradiance for One Axis Tracking PV Systems." Presented at the IEEE Photovoltaic Specialists Conference (PVSC), Washington, D.C, June 25-30, 2017.

Vignola, F., J. Peterson, C. Chiu, M. Dooraghi, M. Sengupta, and F. Mavromatakis. 2017. "Comparison of Pyramometers and Reference Cells on Fixed and One-Axis Tracking Surfaces." Presented at the American Solar Energy Society Conference, Denver, Colorado, October 9-12, 2017.

Xie, Y., and M. Sengupta. 2017. "Toward Improved Modeling of Spectral Solar Irradiance for Solar Energy Applications." Presented at the European PV Solar Conference and Exhibition (EU PVSEC), September 25-29, 2017. 
Xie, Y., and M. Sengupta. 2018. "Validation of the Fast All-sky Radiation Model for Solar applications with Narrowband Irradiances on Tilted surfaces (FARMS-NIT)." Presented at the World Conference on Photovoltaic Energy Conversion (WCPEC-7), June 10-15, 2018.

Vignola, F., J. Peterson, R. Kessler, M. Dooraghi, M. Sengupta, and F. Mavromatakis. 2018.

"Evaluation of Photodiode-Based Pyramometers and Reference Solar Cells on a Two-Axis Tracking System." Presented at the World Conference on Photovoltaic Energy Conversion (WCPEC-7), June 10 15, 2018.

Xie, Y., and M. Sengupta. 2018. "Assessment of Error Sources in the Modeling of POA Irradiance Under Clear-Sky Conditions." Presented at the European PV Solar Conference and Exhibition (EU PVSEC) 2018, September 24-28, 2018. 


\section{References}

Badescu, V. 2002. "3D Isotropic Approximation for Solar Diffuse Irradiance on Tilted Surfaces." Renewable Energy 26: 221-223.

Blair, N., A. Dobos, J., Freeman, T., Neises, M., Wagner, T., Ferguson, P., Gilman, and S. Janzou. 2014. System Advisor Model, SAM 2014.1. 14: General Description (Technical Report NREL/TP-6A2061019). Golden, CO: National Renewable Energy Laboratory.

Branker, K., M. Pathak, and J. Pearce. 2011. "A Review of Solar Photovoltaic Levelized Cost of Electricity." Renewable and Sustainable Energy Review 15: 4470-4482.

Braslau, N., and J. Dave. 1973. "Effect of Aerosols on the Transfer of Solar Energy through Realistic Model Atmospheres. Part I: Non-Abosrbing Aerosols." Journal of Applied Meteorology 12: 601-615.

Chandrasekhar, S. 1950. Radiative Transfer. Oxford: Oxford University Press.

Clough, S., M. Shephard, E. Mlawer, J. Delamere, M. Iacono, K. Cady-Pereira, S. Boukabara, and P.D. Brown. 2005. "Atmospheric Radiative Transfer Modeling: A Summary of the AER Codes." Journal of Quantitative Specrtroscopy and Radiative Transfer 91 (2): 233-244.

Ding, S.G., Y. Xie, P., Yang, F.Z., Weng, Q.H. Liu, B. Baum, and Y.X. Hu. 2009. "Estimates of Radiation Over Clouds and Dust Aerosols: Optimized Number of Terms in Phase Function Expansion." Journal of Quantitative Specrtroscopy and Radiative Transfer 110 (13): 1190-1198.

Dragsted, J. 2011. Solar Heating in Greenland: Resource Assessment and Potential. Denmark: Department of Civil Engineering. Technical University of Denmark.

Fahrenbruch, A., and R. Bube. 1983. Fundamentals of Solar Cells: Photovoltaic Solar Energy Conversion. New York: Academic Press Inc.

Gueymard, C. 1987. "An Anisotropic Solar Irradiance Model for Tilted Surfaces and its Comparison with Selected Engineering Algorithms." Solar Energy 38: 367-386.

Gueymard, C. 1995. SMARTS2: A Simple Model of the Atmospheric Radiative Transfer of Sunshine: Algorithms and Performance Assessment. Cocoa, FL: Florida Solar Energy Center Cocoa.

Gueymard, C., and J. Ruiz-Arias, 2016. "Extensive Worldwide Validation and Climate Sensitivity Analysis of Direct Irradiance Predictions from 1-min Global Irradiance." Solar Energy 128: 1-30.

Hong, G., P. Yang, B.A. Baum, A.J. Heymsfield, and K.M. Xu. 2009. "Parameterization of Shortwave and Longwave Radiative Properties of Ice Clouds for Use in Climate Models." Journal of Climate 22 (23): 6287-6312.

IAMAP. 1986. A Preliminary Cloudless Standard Atmosphere for Radiation Computation. Geneva, Switzerland: World Meteorological Organization. 
Jakhrani, A., A. Othman, A. Rigit, S. Samo, and S. Kamboh. 2012. "Estimation of Incident Solar Radiation on Tilted Surface by Different Empirical Models." International Journal of Scientific and Research Publications 2 (12): 1-6.

Kamali, G., I. Moradi, and A. Khalili. 2006. "Estimating Solar Radiation on Tilted Surfaces with Various Orientations: A Study Case in Karaj (Iran)." Theoretical and Applied Climatology 84: 235-241.

Khalili, S., and A. Shaffie. 2013. "A Comparative Study of Total, Direct and Diffuse Solar Irradiance by Using Different Models on Horizontal and Inclined Surfaces for Cairo, Egypt." Renewable and Sustainable Energy Reviews 27: 853-863.

Kotchenova, S., E. Vermote, R. Matarrese, and F. Klemm. 2006. "Validation of a Vector Version of the 6S Radiative Transfer Code for Atmospheric Correction of Satellite Data. Part I: Path Radiance." Applied Optics 45 (26): 6762-6774.

Lave, M., W. Hayes, A. Pohl, and C. Hansen. 2015. "Evaluation of Global Horizontal Irradiance to Plane-of-Array Irradiance Models at Locations Across the United States." Journal of Photovoltaics 5 (2): 597-606.

Lawless, R., Y. Xie, and P. Yang. 2006. "Polarization and Effective Mueller Matrix for Multiple Scattering of Light by Nonspherical Ice Crystals." Optics Express 14 (14): 6381-6393.

Liou, K.N. 2002. An Introduction to Atmospheric Radiation, 2nd ed. Amsterdam, Boston: Academic Press.

Liu, B., and R. Jordan. 1961. "Daily Insolation on Surfaces Tilted Towards the Equator." ASHRAE Journal 3: 53-59.

Loutzenhiser, P., H. Manz, C. Felsmann, P. Strachan, T. Frank, and G. Maxwell. 2007. "Empirical Validation of Models to Compute Solar Irradiance on Inclined Surfaces for Buiding Energy Simulation." Solar Energy 81: 254-267.

Maxwell, E. 1987. "A Quasi-Physical Model for Converting Hourly Global Horizontal to Direct Normal Insolation." Golden, CO: Solar Energy Research Institution.

McCluney, R., and C. Gueymar. 1993. Sunspec 1.0 Operating Manual. Cocoa, FL: Florida Solar Energy Center.

Meador, W.E., and W.R. Weaver. 1980. "Two-Stream Approximations to Radiative Transfer in Planetary Atmospheres: A Unified Description of Existing Methods and a New Improvement." Journal of Atmospheric Sciences 37: 630-643.

Mojiri, A., R. Taylor, E. Thomsen, and G. Rosengarten. 2013. "Spectral Beam Splitting for Efficient Conversion of Solar Energy_A Review." Renewable and Sustainable Energy Reviews 28: 645-663.

Myers, D. 2012. "Direct Beam and Hemispherical Terrestrial Solar Spectral Distributions Derived from Broadband Hourly Solar Radiation Data." Solar Energy 86 (9): 2771-2782. 
Nann, S., and C. Riordan. 1991. "Solar Spectral Irradiance Under Clear and Cloudy Skies:

Measurements and a Semiempirical Model." Journal of Applied Meteorology 30 (4): 447-462.

Noorian, A., I. Moradi, and G. Kamali. 2008. "Evaluation of 12 Models to Estimate Hourly Diffuse Irradiation on Inclined Surfaces." Renewable Energy 33: 1406-1412.

Pandey, C., and A. Katiyar. 2009. "A Note on Diffuse Solar Radiation on a Tilted Surface." Energy 34: 1764-1769.

Perez, R., P. Ineichen, R. Seals, and J. Michalsky. 1990. "Modeling Daylight Availability and Irradiance Components from Direct and Global Irradiance." Solar Energy 44: 271-289.

Perez, R., Seals, R., Ineichen, P., Stewart, R., and D. Menicucci. 1987. "A New Simplified Version of the Perez Diffuse Irradiance Model for Tilted Surfaces." Solar Energy 39 (3): 221-231.

Reindl, D., W. Beckman, and J. Duffie. 1990. "Evaluation of Hourly Tilted Surface Radiation Models." Solar Energy 45 (1): 9-17.

Sengupta, M., A. Habte, P. Gotseff, A. Weekley, A. Lopez, C. Molling, and A. Heidinger. 2014. "A Physics-Based GOES Product for Use in NREL's National Solar Radiation Database." Presented at the European Photovoltaic Solar Energy Conference and Exhibition, Amsterdam, Netherlands.

Sengupta, M., Y. Xie, A. Lopez, A. Habte, G. Maclaurin, and J. Shelby. 2018. "The National Solar Radiation Data Base (NSRDB)." Renewable and Sustainable Energy Reviews 89: 51-60.

Shettle, E., and R. Fenn. 1979. Models for the Aerosols of the Lower Atmosphere and the Effects of Humidity Variations on Their Optical Properties. Hanscom, MA: Air Force Geophysics Lab.

Stamnes, K., S.C. Tsay, W. Wiscombe, and K. Jayaweera. 1988. "Numerically Stable Algorithm for Discrete-Ordinate-Method Radiative Transfer in Multiple Scattering and Emitting Layered Media." Applied Optics 27 (12): 2502-2509.

Stokes, G.M., and E. Schwartz. 1994. "The Atmospheric Radiation Measurement (ARM) Program: Programmatic Background and Design of the Cloud and Radiation Test Bed." Bulletin of the American Meteorological Society 75 (7): 1201-1221.

Wang, C., P. Yang, S. Nasiri, S. Platnick, B. Baum, A. Heidinger, and X. Liu. 2013. "A Fast Radiative Transfer Model for Visible through Shortwave Infrared Spectral Reflectances in Clear and Cloudy Atmospheres." Journal of Quantitative Specrtroscopy and Radiative Transfer 116: 122-131.

Xie, Y. 2010. "Study of Ice Cloud Properties from Synergetic Use of Satellite Observations and Modeling Capabilities." Ph.D. diss., Texas A\&M University.

Xie, Y., an M. Sengupta. 2018. "A Fast All-sky Radiation Model for Solar Applications with Narrowband Irradiances on Tilted surfaces (FARMS-NIT): Part I. The Clear-Sky Model." Solar Energy 174: 691-702. 
Xie, Y., M. Sengupta, and M. Dooraghi. 2018. "Assessment of Uncertainty in the Numerical Simulation of Solar Irradiance Over Inclined PV Panels: New Algorithms Using Measurements and Modeling Tools." Solar Energy 165: 55-64.

Xie, Y., M. Sengupta, and J. Dudhia. 2016. "A Fast All-sky Radiation Model for Solar Applications (FARMS): Algorithm and Performance Evaluation." Solar Energy 135: 435-445.

Xie, Y., Y. Yang, B.C. Gao, G.W. Kattawar, and M.I. Mishchenko. 2006. "Effect of Ice Crystal Shape and Effective Size on Snow Bidirectional Reflectance." Journal of Quantitative Specrtroscopy and Radiative Transfer 100 (1-3): 457-469.

Xie, Y., P. Yang, G.W. Kattawar, B. Baum, and Y.X. Hu. 2011. "Simulation of the Optical Properties of Ice Particle Aggregates for Application to Remote Sensing of Cirrus Clouds." Applied Optics 50: 10651081 .

Xie, Y., P. Yang, G.W. Kattawar, P. Minnis, and Y.X. Hu. 2009. "Effect of the Inhomogeneity of Ice Crystals on Retrieving Ice Cloud Optical Thickness and Effective Particle Size." Journal of Geophysical Research 114: D11203. doi:11210.11029/12008JD011216.

Xie, Y., P. Yang, G.W. Kattawar, P. Minnis, Y.X. Hu, and D. Wu. 2012a. "Determination of Ice Cloud Models Using MODIS and MISR Data." International Journal of Remote Sensing 33: 4219-4253.

Xie, Y., P. Yang, K.N. Liou, P. Minnis, and D.P. Duda. 2012b. "Parameterization of Contrail Radiative Properties for Climate Studies." Geophysical Research Letters 39(L00F02). doi:10.1029/2012GL054043. 